Article

\title{
Analyzing the Relationship between Developed Land Area and Nighttime Light Emissions of 36 Chinese Cities
}

\author{
Hui-min $\mathrm{Li}^{1}$, Xiao-gang $\mathrm{Li}^{2}$, Xiao-ying Yang ${ }^{1}$ and Hao Zhang ${ }^{1, *}$ \\ 1 Department of Environmental Science and Engineering, Jiangwan campus, Fudan University, \\ 2005 Songhu Road, Yangpu District, Shanghai 200438, China; 15210740011@fudan.edu.cn (H.-m.L.); \\ xiaoying@fudan.edu.cn (X.-y.Y.) \\ 2 Jiangxi Province Radiation Environment Supervision Station, 1131 Hongdu Avenue, Nanchang 330077, \\ China; lxiaogang@126.com \\ * Correspondence: zhokzhok@163.com; Tel.: +86-21-3124-8919
}

Received: 6 November 2018; Accepted: 18 December 2018; Published: 20 December 2018

check for updates

\begin{abstract}
The satellite-observed nighttime light emission (NTLE) data provide a new method for scrutinizing the footprint of human settlements. Changing NTLEs can be attributed to the direct/ indirect influences of highly complex factors that are beyond the ability of simple statistical models to distinguish. Besides, the relatively coarse resolution of the NTLE products combined with light from human settlements may produce misleading results, as the relationship between spatiotemporal heterogeneity in the growth of developed land (e.g., urban and rural residences, shopping centers, industrial parks, mining plants, and transportation facilities) and the associated NTLEs has not been adequately analyzed. In this study, we developed a total nighttime brightness index (TotalNTBI) to measure the NTLEs with the defense meteorological satellite program/operational linescan system (DMSP/OLS) nighttime light data enhanced by sharpening the edges of the pixels. Thirty-six key cities in China were selected to investigate the relationship between the total developed land area and the associated TotalNTBI from 2000 to 2013 using panel regression and a simplified structural equation model (SEM). The results show that the overall trend in TotalNTBI agreed well with that of the total developed land area (mean adjusted $R^{2}=0.799$ ). The panel regression models explained approximately $71.8 \%$ of the variance of total developed land area and $92.4 \%$ of the variance in TotalNTBI. The SEM revealed both the direct and indirect influences of independent variables on the total developed land area and the associated TotalNTBI. This study may provide useful information for decision-makers and researchers engaged in sustainable land development, urban management, and regional developmental inequality, focusing on recent issues, such as retrospective analysis of human footprint with sharpened nighttime NTLE products, the loss of natural and semi-natural land due to the sprawling developed land area indicated by intensively lit area, and the low efficiency of land development indicated by the anomalies of developed land area and associated NTBIs.
\end{abstract}

Keywords: China; nighttime light emissions (NTLE); developed land area; total nighttime brightness index (TotalNTBI)

\section{Introduction}

Since the industrial revolution, ongoing population migration from rural regions to urban areas has dominated socioeconomic transition worldwide. Approximately $55 \%$ of people live in cities, and this proportion is expected to increase to $68 \%$ in 2050 [1]. Therefore, studies on the growth patterns and underlying driving factors of human settlements should be placed into the broader context of 
global change, as the role of humans will affect the earth's future [2,3] and eventually determine the fate of human society.

Compared with the conventional census approach with its shortcomings of data scarcity, bias, and uncertainty, the remote sensing of nighttime light emissions (NTLEs) provides a new view method for scrutinizing the footprint of human activities. Nighttime light emissions signals captured by on-board sensors, such as those onboard the defense meteorological satellite program/operational linescan system (DMSP/OLS) in 1992-2013 and the Visible Infrared Imaging Radiometer Suite (VIIRS) since 2012, have accumulated 26 years of nighttime light data. Together with survey and census data, archived nighttime light data effectively reflects the trajectory of human settlements associated with socioeconomic evolution, with a focus on population estimation $[4,5]$, monitoring urban expansion and peri-urbanization [6-12], estimation of economic growth [13], military conflicts, and humanitarian crises [14-16]. These data can therefore be used for an assessment of developmental inequality. For instance, NTLEs can be used as a proxy for measuring human well-being such as electrification rates and economical development [17].

As the largest developing country experiencing industrialization and urbanization since 1978, China has witnessed a dramatic transition from an agriculture-dominated society to one characterized by robust economic growth and an emergence of urban clusters that brighten the nighttime sky. To understand the processes and mechanism of urbanization and land use/land cover (LULC) change during urbanization, researchers have often combined satellite nighttime light data with socioeconomic data to study the magnitude and intensity of human activities, ranging from urbanization [18-22], population [23,24], and socioeconomic development [25-28] to regional inequality [29]. However, two issues remain unsolved in this field. Firstly, existing literature has emphasized the overall relationships between NTLEs and one, two, or more independent variables (e.g., gross domestic product (GDP), population density, and urban extent). Changing NTLEs may be affected by complicated direct or indirect influential factors, which cannot be interpreted by simple statistical methods such as correlation and regression. Secondly, compared with the International Space Station (ISS) NTL images [30], the nighttime human footprints extracted from DMSP/OLS and VIIRS data have generally been too coarse to match the ground-truth of LULC. Enhanced DMSP/OLS products with sharpened edges and validation may help improve these results and help determine the relationship between spatiotemporal heterogeneity of the growth of human settlements and associated NTLEs. Therefore, comprehensive studies focusing on these questions are required to bridge the gap in our knowledge.

In this study, 36 politically, socioeconomically, and culturally important cities in China were selected for a case study (i) to test whether there is a cause-effect relationship between developed land area and associated NTLEs by examining the developed land area and enhanced DMSP/OLS datasets with a sharpened edge and (ii) to determine, if such a relationship exists, the driving factors and their mechanism of action. Our study results can provide a scientific basis for the creation of policy measures for sustainable land development and urban management in China and elsewhere with similar conditions.

\section{Study Area}

Figure 1 shows the location of the 36 cities in China. According to China's current administrative ranking system of cities, these cities were classified into three prefecture ranks in descending importance from municipalities directly under the central government to provincial cities and sub-provincial cities (Table 1). In terms of geographic zoning, these cities are the largest and most representative urban agglomerations in their corresponding geographical zones, varying in natural conditions, socioeconomic complexity, and developmental inequality. At the end of 2013, these cities accommodated 299.39 million people and produced 23.72 trillion RMB Yuan GDP, accounting for $21.99 \%$ of the total population and $39.85 \%$ of the total GDP [31], respectively. 


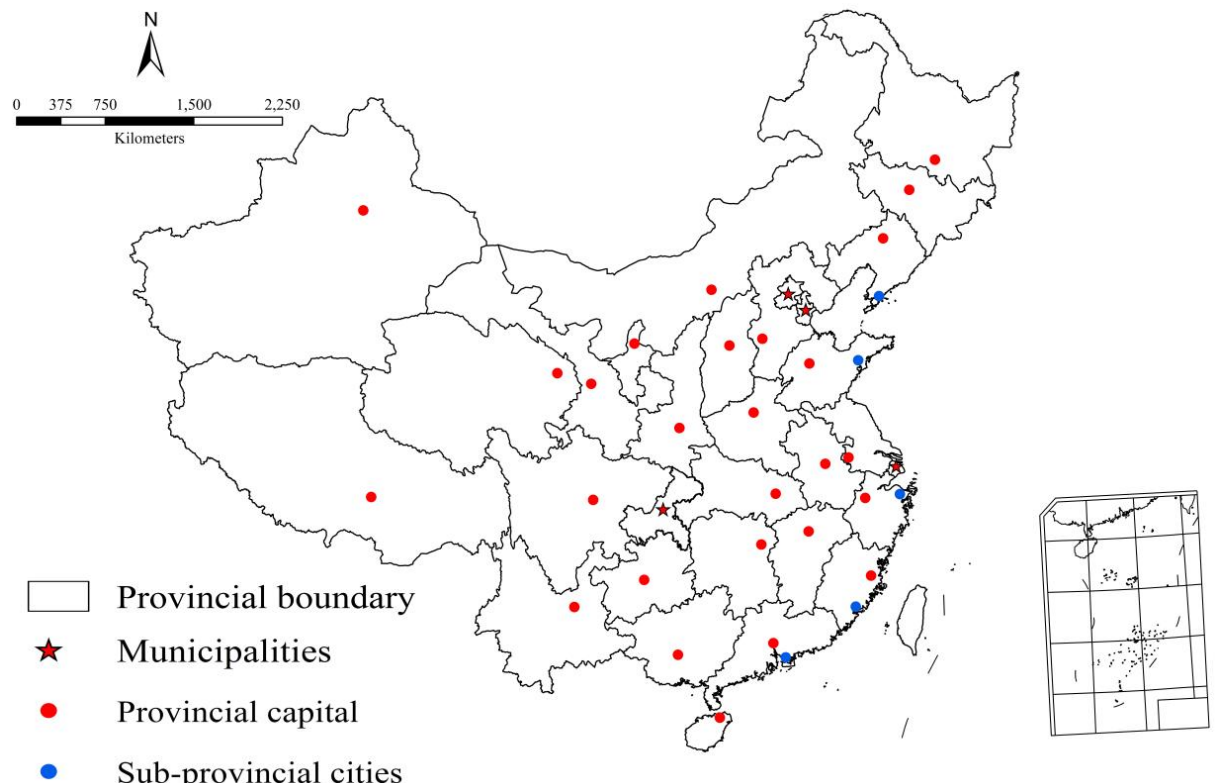

Figure 1. Geolocation of 36 key cities in China. The inset shows the islands in the South China Sea.

Table 1. Description of 36 key cities [31] in China.

\begin{tabular}{|c|c|c|c|c|c|c|c|}
\hline $\begin{array}{l}\text { Geographical } \\
\text { Zoning }\end{array}$ & City & Province & Prefecture Rank & Population & GDP & Agr_Pop & Agr_GDP \\
\hline \multirow{5}{*}{$\begin{array}{l}\text { Northern } \\
\text { China }\end{array}$} & Beijing & - & Municipality & 21.148 & 1.950 & 0.123 & 0.578 \\
\hline & Tianjin & - & Municipality & 14.722 & 1.437 & 0.096 & 0.362 \\
\hline & Shijiazhuang & Hebei & Provincial capital & 10.032 & 0.491 & 0.015 & 0.045 \\
\hline & Taiyuan & Shanxi & Provincial capital & 3.675 & 0.241 & 0.029 & 0.087 \\
\hline & Hohhot & Inner Mongolia & Provincial capital & 3.001 & 0.271 & 0.019 & 0.070 \\
\hline \multirow{4}{*}{$\begin{array}{l}\text { Northeastern } \\
\text { China }\end{array}$} & Shenyang & Liaoning & Provincial capital & 8.257 & 0.716 & 0.046 & 0.081 \\
\hline & Dalian & Liaoning & sub-Provincial city & 6.943 & 0.727 & 0.047 & 0.110 \\
\hline & Changchun & Jilin & Provincial capital & 7.527 & 0.500 & 0.032 & 0.041 \\
\hline & Harbin & Heilongjiang & Provincial capital & 9.952 & 0.502 & 0.030 & 0.047 \\
\hline \multirow{10}{*}{ Eastern China } & Shanghai & - & Municipality & 24.152 & 2.160 & 0.125 & 0.620 \\
\hline & Nanjing & Jiangsu & Provincial capital & 8.178 & 0.801 & 0.052 & 0.210 \\
\hline & Hangzhou & Zhejiang & Provincial capital & 7.066 & 0.834 & 0.052 & 0.065 \\
\hline & Ningbo & Zhejiang & sub-Provincial city & 7.663 & 0.713 & 0.045 & 0.173 \\
\hline & Hefei & Anhui & Provincial capital & 7.610 & 0.476 & 0.033 & 0.242 \\
\hline & Fuzhou & Fujian & Provincial capital & 7.340 & 0.468 & 0.028 & 0.111 \\
\hline & Xiamen & Fujian & sub-Provincial city & 3.730 & 0.302 & 0.019 & 0.129 \\
\hline & Jinan & Shandong & Provincial capital & 6.133 & 0.523 & 0.032 & 0.039 \\
\hline & Qingdao & Shandong & sub-Provincial city & 8.964 & 0.801 & 0.051 & 0.146 \\
\hline & Nanchang & Jiangxi ${ }^{\circ}$ & Provincial capital & 5.101 & 0.334 & 0.022 & 0.060 \\
\hline \multirow{3}{*}{ Central China } & Wuhan & Hubei & Provincial capital & 8.221 & 0.905 & 0.059 & 0.056 \\
\hline & Changsha & Hunan & Provincial capital & 6.628 & 0.715 & 0.049 & 0.059 \\
\hline & Zhengzhou & Henan & Provincial capital & 9.191 & 0.620 & 0.041 & 0.224 \\
\hline \multirow{4}{*}{$\begin{array}{l}\text { Southern } \\
\text { China }\end{array}$} & Guangzhou & Guangdong & Provincial capital & 8.323 & 1.542 & 0.097 & 0.106 \\
\hline & Shenzhen & Guangdong & sub-Provincial city & 10.629 & 1.450 & 0.093 & 0.278 \\
\hline & Nanning & Guangxi & Provincial capital & 7.244 & 0.280 & 0.018 & 0.333 \\
\hline & Haikou & Hainan & Provincial capital & 2.171 & 0.088 & 0.005 & 0.051 \\
\hline \multirow{5}{*}{$\begin{array}{l}\text { Southwestern } \\
\text { China }\end{array}$} & Chongqing & - & Municipality & 29.700 & 1.266 & 0.082 & 0.093 \\
\hline & Chengdu & Sichuan & Provincial capital & 14.350 & 0.911 & 0.059 & 0.249 \\
\hline & Kunming & Yunnan & Provincial capital & 6.579 & 0.342 & 0.021 & 0.136 \\
\hline & Guiyang & Guizhou & Provincial capital & 4.522 & 0.209 & 0.014 & 0.093 \\
\hline & Lhasa & Tibet & Provincial capital & 0.601 & 0.030 & 0.002 & 0.010 \\
\hline \multirow{5}{*}{$\begin{array}{l}\text { Northwestern } \\
\text { China }\end{array}$} & Urumchi & Xinjiang & Provincial capital & 3.460 & 0.220 & 0.014 & 0.126 \\
\hline & Lanzhou & Gansu & Provincial capital & 3.642 & 0.178 & 0.011 & 0.057 \\
\hline & Xining & Qinghai & Provincial capital & 2.268 & 0.098 & 0.007 & 0.022 \\
\hline & Yinchuan & Ningxia & Provincial capital & 2.083 & 0.129 & 0.009 & 0.063 \\
\hline & Xi'an & Shaanxi & Provincial capital & 8.588 & 0.488 & 0.032 & 0.091 \\
\hline
\end{tabular}

Note: This table only shows regional population (in million persons) and gross domestic production (GDP) (in trillion RMB Yuan) in 2013, which is the reference year for this study. AGR_Pop and AGR_GDP denote annual grow rate of population (million persons per year) and annual grow rate of GDP (trillion RMB Yuan per year) during 2000 and 2013, respectively. 


\section{Materials and Methods}

\subsection{Datasets}

In this study, socioeconomic, China national LULC, and DMSP/OLS nighttime with stable lights (Version 4) data, and the standardized digital boundary layer, were used. Selection of socioeconomic data was a challenge given the missing values among these key cities across the study period. Considering the availability, representativeness, and comparability of the socioeconomic data among the key cities, we selected six essential socioeconomic variables from 2000 to 2013, which were extracted from China's statistical yearbook [31].

The 250 m national LULC data for 2000, 2005, 2008, 2010, and 2013, produced based on the land classification of Landsat Thematic Mapper (TM), the Enhanced Thematic Mapper plus (ETM+), and the Operational Land Imager (OLI) imagery and validated with a field survey, were provided by Beijing Digital View Technology Co., Ltd. (Beijing, China). The 1:4,000,000 standardized digital boundaries of China's provinces and cities were acquired from China National Geomatics Center. Due to its relatively short time span and the lack of annually corrected product, the VIIRS nighttime data were not used. Instead, 1-km-resolution DMSP/OLS nighttime data (https:/ / ngdc.noaa.gov/eog/index.html) with stable lights (Version 4) from 2000 to 2013 were used.

\subsection{Methods}

\subsubsection{Data Preprocessing}

The data preprocessing procedures included the transformation of the geographic coordinate system (GCS) and universal transverse Mercator (UTM) projection, georeferencing, resampling, and clipping. Firstly, all data were transformed into Beijing 1954 GCS with the UTM project (WGS 1984, 43-53N), given the popularity of the UTM system and the possibility of international comparison. Secondly, for each of the 36 largest cities, a large extent covering each urban cluster (including the largest city and its surrounding cities) was clipped. The UTM conversion for each urban cluster was performed according to their specific UTM zone coding, by using the second-order polynomial method, both the DMSP/OLS and LULC data in each year were georeferenced by matching with 100 ground control points (GCPs), which were selected from the 1:4,000,000 standardized digital boundaries of China. The acceptable root mean square error (RMSE) was within one pixel. Thirdly, all georeferenced layers were resampled to $250 \mathrm{~m}$ resolution and used for sharpening the edges of DMSP/OLS data via visual refinement. Finally, the georeferenced layers were clipped with the standardized digital boundaries of the 36 cities for detailed analysis.

\subsubsection{Generation of Enhanced DMSP/OLS Data}

Although the detectable signal noise from wild fires, gas flares, and fishing boats were removed, DMSP/OLS nighttime data with stable lights cannot be directly used to characterize the extent of human settlements due to the over-saturation of the city core and inter-annual variation of onboard sensors [32,33]. In this study, steps to enhance the DMSP/OLS data included reducing inter-annual variation, sharpening edges, and validating the results. Examining the DMSP/OLS data series revealed an overall increasing trend in the brightness (digital number/DN value) of the developed land area across the study period. In Step 1, the brightest F182013 scene was used as the baseline for reducing inter-annual variation in the DMSP/OLS datasets, whose DN values in other years were calibrated using the polynomial model [34]. Step 2 included edge sharpening of the scene. We assumed that areas with stable, artificial light at nighttime exist in human settlements. The $250 \mathrm{~m}$ LULC data and the calibrated DMSP/OLS data were overlaid with a binary layer of background pixels and developed land, which was changed from natural or semi-natural lands for permanent development of urban and rural settlements. With a value of 0 , background pixels represented semi-natural and natural land cover. Referencing China's national standard of land use classification [35], the developed land, including its 
three sub-categories, namely urban developed land (e.g., urban residences, shopping centers, schools, and ring roads), rural developed land (e.g., rural residences, countryside roads, dams and dikes), and other developed land (e.g., industrial parks, mining plants, military bases, warehouse, airports, and harbor facilities), was valued as 1. Edge sharpening of the DMSP/OLS data was achieved using Equation (1).

$$
\mathrm{DN}^{*}=\mathrm{DN} \times \text { Layer_Target }
$$

where $\mathrm{DN}^{*}$ is the corrected DN value of DMSP/OLS data, DN is the initial DN value of DMSP/OLS data, and Layer_Target is a binary layer (0 for background pixels, and 1 for human settlements).

Step 3 included the validation of enhanced DMSP/OLS data. In this step, for each city, the enhanced DMSP/OLS data were overlapped with the Landsat TM/ETM+/8 images and historical Google Earth images. A series of pixels along the invariant urban-rural gradient was sampled to check for unstable changes across the study period, especially the potential loss or exaggeration of brightness in urban centers and intensive rural settlements. Several specific regression models (Table S1) were employed to adjust the threshold of the lit area in the enhanced DMSP/OLS data. Finally, to maintain the data consistency between the raw and enhanced DMSP/OLS data, the DNs of enhanced DMSP/OLS data were rescaled to the interval of 0-63 [36]. Raw and enhanced DMSP/OLS data is shown in Figure 2.

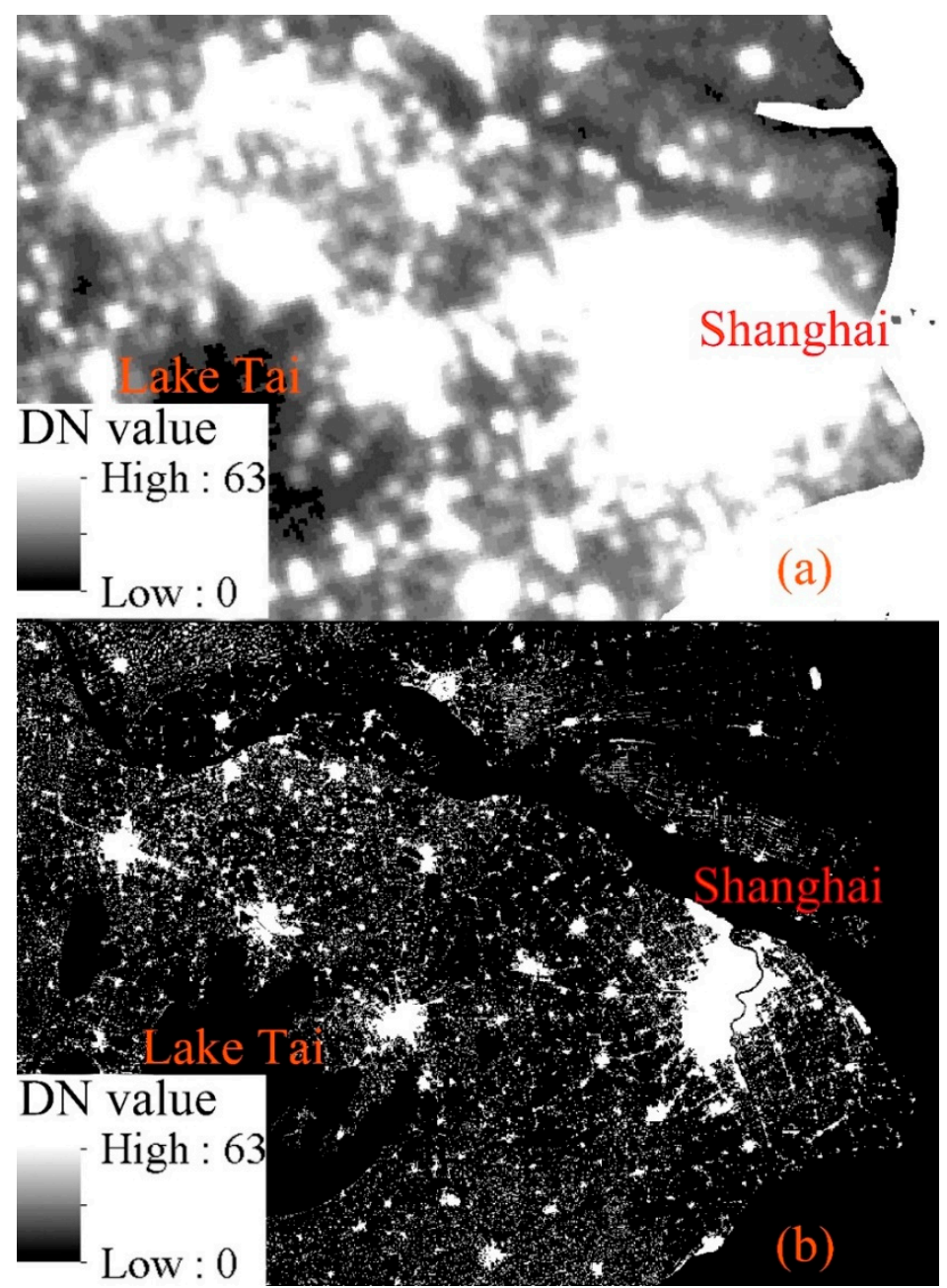

Figure 2. The digital number (DN) values of (a) raw and (b) enhanced DMSP/OLS data. 


\subsubsection{Measurement of NTLE}

Within each city's domain, NTLE was measured with the TotalNTBI, which is the sum of three sub-level NTBIs associated with the areas of urban developed land (UrbanNTBI), rural developed land (RuralNTBI), and other developed land (OtherNTBI). The formulas for calculating these indices, respectively, are as follows:

$$
\begin{array}{r}
\text { TotalNTBI }=\text { UrbanNTBI }+ \text { RuralNTBI }+ \text { OtherNTBI } \\
\text { UrbanNTBI }=\sum_{i=1}^{n} P_{i} \times N_{i} \\
\text { RuralNTBI }=\sum_{j=1}^{n} P_{j} \times N_{j} \\
\text { OtherNTBI }=\sum_{k=1}^{n} P_{k} \times N_{k}
\end{array}
$$

where $P_{i}, P_{j}$, and $P_{k}$ are the per pixel-based unitless DN values associated with urban developed land, rural developed land, and other developed land, respectively; $N_{i}, N_{j}$, and $N_{k}$ are pixel counts of $P_{i}$, $P_{j}$, and $P_{k}$, respectively. Therefore, for a given city, the TotalNTBI and its three sub-level NTBIs were characterized with the cumulative unitless DN values (CUDVs) of clustered pixels associated with the spatial extents of total developed land and its three sub-categories (Figure S2).

\subsubsection{Statistical Analysis}

To quantitatively examine the overall relationship between the total developed land area and the associated TotalNTBI, we applied panel regression models considering both the random and fixed effects. With developed land area as the dependent variable, the model is:

$$
\text { Developed }=\alpha+\beta_{1} \times \text { GDP }_{i, t}+\beta_{2} \times \text { POP }_{i, t}+\beta_{3} \times \text { Second }_{i, t}+\beta_{4} \times \text { Third }_{i, t}+\beta_{5} \times \text { Mileage }_{i, t}+\beta_{6} \times \text { Freight }_{i, t}+U_{i, t}
$$

where Developed denotes the total area of developed land, $\alpha$ is a constant, $\beta_{1}-\beta_{6}$ are coefficients of the independent variables described in Table $2, i$ is the city, $t$ is the year, and $U_{i, t}$ is the individual-specific, time-invariant effects plus a time-varying random component.

Table 2. Description of socioeconomic variables [31].

\begin{tabular}{cc}
\hline Variable & Description \\
\hline GDP & Gross domestic production of the city (unit: trillion RMB Yuan) \\
POP & Population size of the city (unit: million person) \\
Secondary & The share of secondary industry in GDP \\
Tertiary & The share of tertiary industry in GDP \\
Mileage & Mileage of paved roads (unit: kilometer) \\
Freight & The total volume of freight transport, including wheel transport, shipment, and airlift (unit: ton) \\
\hline
\end{tabular}

Similarly, with TotalNTBI as the dependent variable, the model is:

$$
\begin{aligned}
\ln (\text { TotalNTBI })=\alpha+\beta_{1} \times \text { GDP }_{i, t}+\beta_{2} \times \text { POP }_{i, t}+\beta_{3} \times \text { Second }_{i, t}+\beta_{4} \times \text { Third }_{i, t}+\beta_{5} \times \text { Mileage }_{i, t} \\
+\beta_{6} \times \text { Freight }_{i, t}+\beta_{7} \times \text { Developed }_{i, t}+U_{i, t}
\end{aligned}
$$

where $\ln$ (TotalNTBI) is the natural logarithm of TotalNTBI, and $\beta_{7}$ is the coefficient of the total developed land area.

The Hausman Test was performed to find any inconsistency between the random and fixed effects [37].

A structural equation model (SEM), which highlights the relative sensitivity of the total developed land area and the associated TotalNTBI in response to changing percentage of the socioeconomic variables, was used to examine the abovementioned relationships. Numerous possible paths, including both simple and complicated conceptual models that considered both one-way and two-way relationships between the dependent and independent variables, were tested and compared. Simpler 
models may clearly exhibit linkages with the risk of ignoring potentially vital effects, whereas complicated models may better capture all possible relationships with confusing results. Given this trade-off, alternative linkages with logical soundness for better interpreting the relationships between the dependent and independent variables were refined, by introducing or deleting the possible direct/indirect linkages between the variables, which were verified with relatively high correlation coefficients. Finally, a simplified but more straightforward SEM, which was more interpretable and captured the essence of the abovementioned relationships, was employed to quantify the changes in socioeconomic variables and their influence on the regional developed land area and the associated TotalNTBI.

In this study, the statistical processes were performed with the basic functions of R 3.5.1 and the key libraries, such as the plm, dplyr, sem, and pathDiagram.

\section{Results}

\subsection{Synaptic Analysis of Growth Patterns of Developed Land}

Figure 3 shows the overall trends in total developed land and the three sub-levels of developed land in the 36 cities from 2000 to 2013. Total developed land increased by $64.53 \%$ from $28,947.75 \mathrm{~km}^{2}$ in 2000 to $47,626.94 \mathrm{~km}^{2}$ in 2013, with an annual mean growth rate of $39.91 \mathrm{~km}^{2}$ (Figure 3a). However, the increase in total developed land exhibited considerable spatial variability. Annual growth rates of 16 cities were higher than the annual mean growth rate, ranging from $40.87 \mathrm{~km}^{2} /$ year in Wuhan (total developed land increased 0.81-fold) to $134.78 \mathrm{~km}^{2} /$ year in Beijing (total developed land increased 0.76-fold). Annual growth rates of the remaining cities ranged from $0.67 \mathrm{~km}^{2} /$ year in Lhasa (total developed land increased 0.16-fold) to $36.55 \mathrm{~km}^{2} /$ year in Urumqi (total developed land increased 1.46-fold). Figure $3 \mathrm{~b}-\mathrm{d}$ demonstrate the differences in the growth patterns of the three sub-categories of developed land. Urban developed land showed a fast-growing pattern in the leading cities of Northern China (e.g., Beijing, Tianjin, and Shijiazhuang), Eastern China (e.g., Shanghai, Nanjing, Jinan, and Qingdao), Southern China (e.g., Guangzhou and Shenzhen), Central China (e.g., Zhengzhou), and Southwestern China (Chengdu and Chongqing). An overall moderate growth pattern was observed in other cities in Eastern China (e.g., Hangzhou, Ningbo, and Hefei), Northeastern China (e.g., Changchun, Dalian, and Shenyang), Central China (e.g., Changsha and Wuhan), and Northwestern China (e.g., Urumqi and $\mathrm{Xi}^{\prime}$ an). In contrast, urban developed land exhibited an overall slower growth pattern in some cities in less developed provinces (e.g., Taiyuan, Hohhot, Nanchang, Nanning, Haikou, Lhasa, Guiyang, Kunming, Taiyuan, and Xining). However, two coastal cities, Fuzhou and Xiamen with prosperous economies, also exhibited a lower growth pattern due to terrain constraining urban expansion.

Figure $3 \mathrm{c}$ shows the overall growth pattern of rural developed land, similar to Figure $3 a$, regardless of their geographical regions and socioeconomic development level. The exceptions were 11 cities, among which Changchun and Guangzhou exhibited the overall decreasing trend in the rural developed land, while Xiamen, Nanchang, Changsha, Wuhan, Shenzhen, Nanning, Haikou, Guiyang, and Lhasa exhibited unchanging rural developed land. Figure $3 \mathrm{~d}$ showed the power or exponential increase in the other developed land in the traditional industrial cities such as Tianjin, Dalian, Shanghai, Wuhan, Changsha, Guangzhou, Chongqing, and Urumqi. The growth pattern of the other developed land in Beijing, Nanjing, and Qingdao exhibited an initially increasing but subsequently decreasing trend. In contrast, the growth pattern of the other developed land in Hohhot, Lhasa, and Xining generally exhibited a low expansion in areal extent with slight variation. 


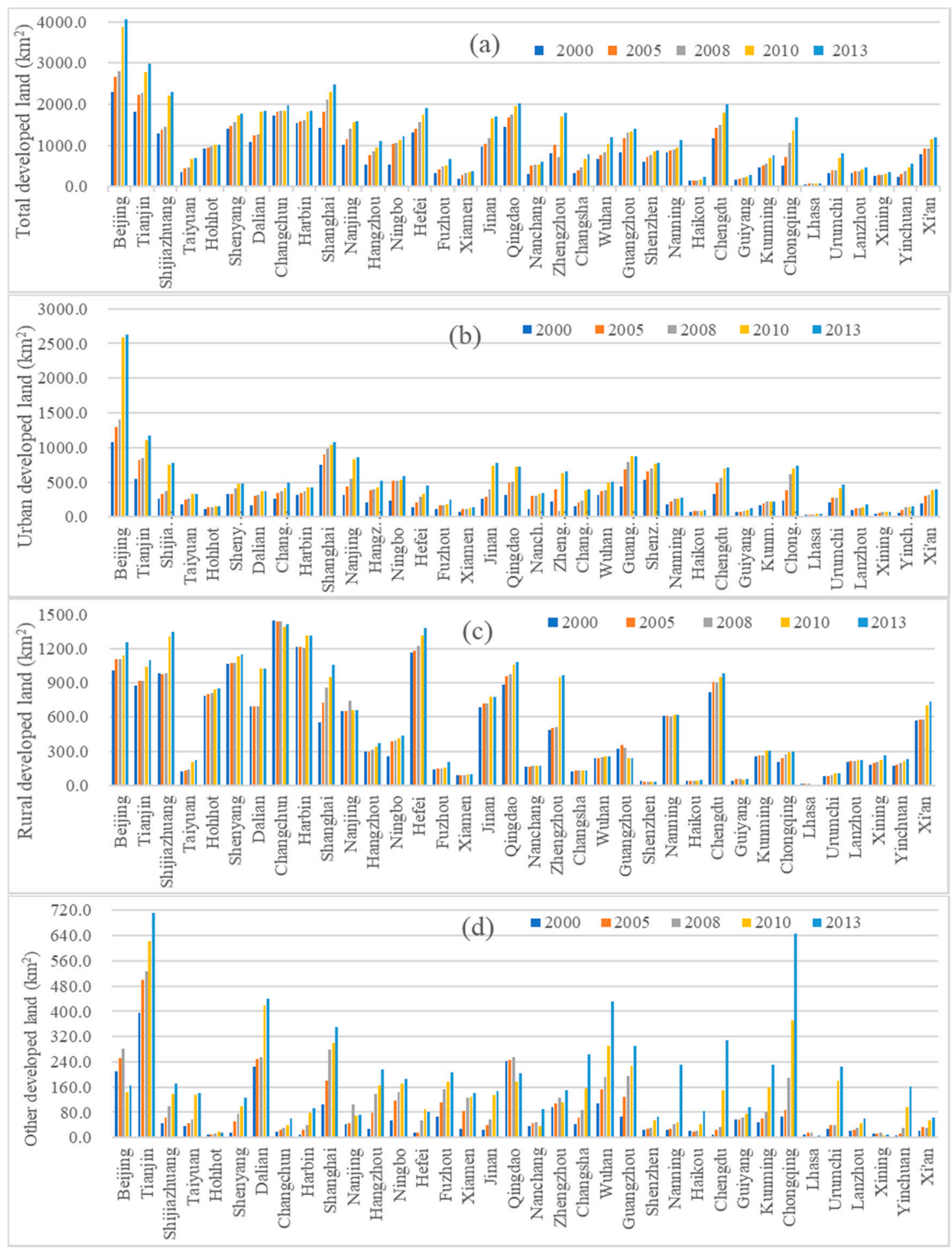

Figure 3. Dynamics of the developed land within the city's boundary in 2000-2013: (a) total, (b) urban, (c) rural, and (d) other developed land.

\subsection{The Dynamics of NTBI in Response to Developed Land Growth}

Figure 4 depicts the overall trends in TotalNTBI, UrbanNBI, RuralNBI, and OtherNBI in the 36 cities from 2000 to 2013 . According to Figure $4 a$, TotalNTBI increased $146.29 \%$ from a CUDV of $1156.74 \times 10^{4}$ to a one of $2849.05 \times 10^{4}$, with an annual growth rate of $130.18 \times 10^{4}$. Generally, the trend in TotalNTBI was similar to that in Figure 2a. Leading cities, such as Beijing, Tianjin, Shanghai, 
Hangzhou, Ningbo, Chengdu, Guangzhou, and Shenzhen, exhibited much higher TotalNTBI. Cities in less-developed provinces exhibited lower TotalNTBI. However, Shenyang, Dalian, Harbin, Changchun, and Hefei did not exhibit higher TotalNTBI in proportion to their larger amount of total developed land. Figure $4 \mathrm{~b}$,d show that trends in UrbanNTBI and OtherNTBI were in good agreement with those of urban developed land and other developed land shown in Figure $3 b$,d, respectively, since urban developed land and other developed land were the dominant contributors to TotalNTBI. However, the relationship between rural developed land area and RuralNTBI was relatively weak. For example, in Shenyang, Dalian, Harbin, Changchun, and Hefei, although their rural developed land area was much larger than urban developed land area, their RuralNTBI values were much lower than UrbanNTBI. These trends were evidenced by the dynamics of lit area in response to the growth of developed land of representative cities (Figures 5 and 6). The inconsistency between the total developed land area and the associated TotalNTBI could partly be explained by the biased RuralNTBI.

Figure 7 demonstrates the significant variation in inter-city TotalNTBI in response to changes in the total developed land area. Most of the scatter points followed the pattern whereby the greater the total developed land area, the higher the associated TotalNTBI. As can be seen, Beijing, Tianjin, and Shanghai were the top megacities, whose total developed land area and associated TotalNTBI surpassed that of the other cities. The scatter points falling within the middle section of the curves showed a close relationship between the total developed land area and the associated TotalNTBI in 18 typical megacities, including Shijiazhuang, Zhengzhou, Xi'an, Jinan, Qingdao, Chengdu, Guangzhou, Shenzhen, Nanjing, Hangzhou, and Ningbo. However, for Naning and Hohhot, there was an apparent mismatch between total developed land area and the associated TotalNTBI, though their total developed land area was greater than that of Hangzhou, Shenzhen, and Wuhan, but with a much lower TotalNTBI. As shown in Figures 2 and 4, the dominant share of rural development land in the total developed land with a lower RuralNTBI partly explains the mismatched relationship in these two cities. Additionally, cities belonging to the left bottom section of the curve with a steeper slope were located in the less-developed Northwestern and Southwestern China. Their change in total developed land area was in good agreement with TotalNTBI. 


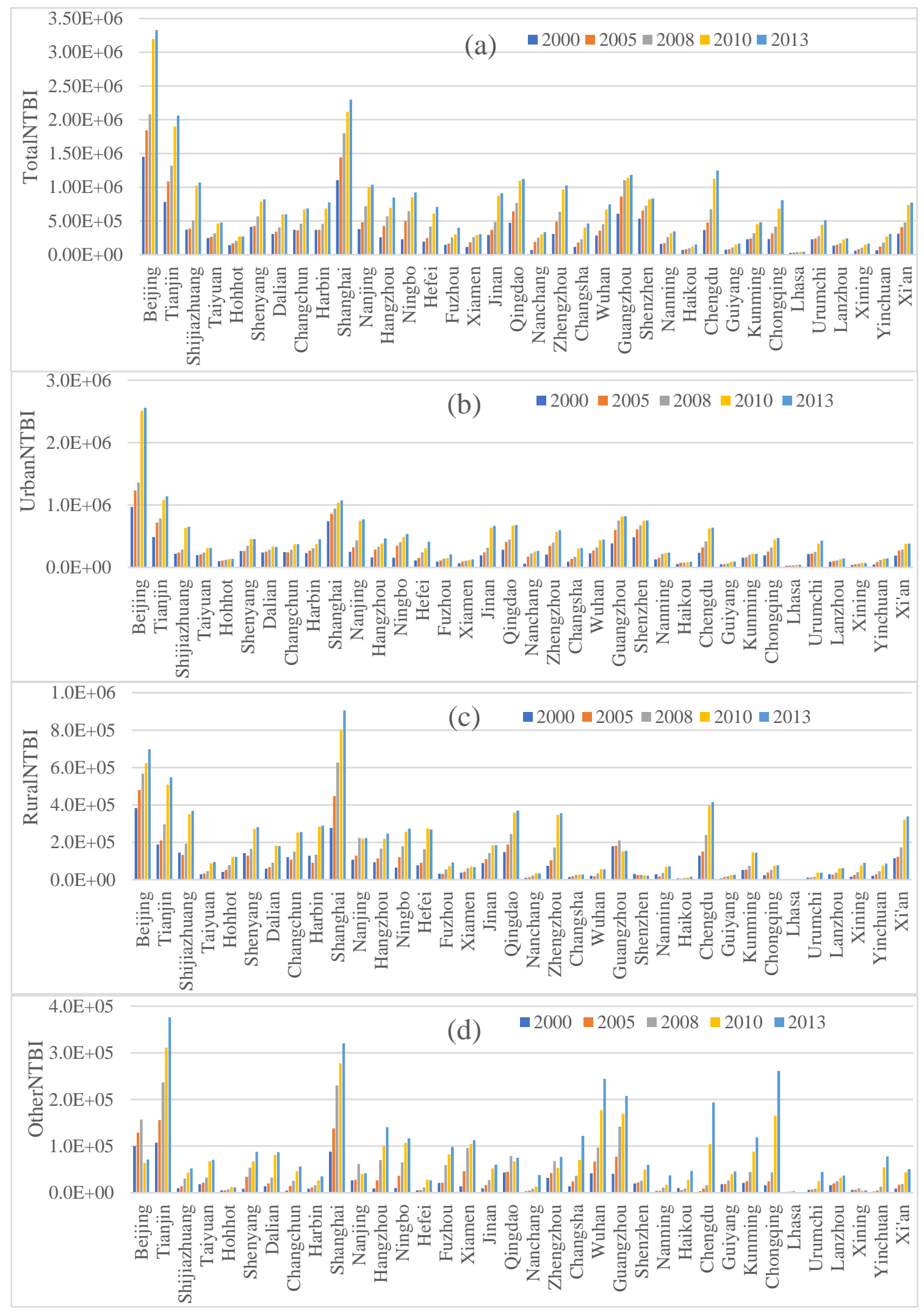

Figure 4. Trends in (a) TotalNTBI associated with total developed land area, (b) UrbanNTBI associated with urban developed land area, (c) RuralNTBI associated with rural developed land area, and (d) OtherNTBI associated with other developed land area, within the cities' boundaries in 2000-2013 characterized with a cumulative unitless DN value (CUDV). 


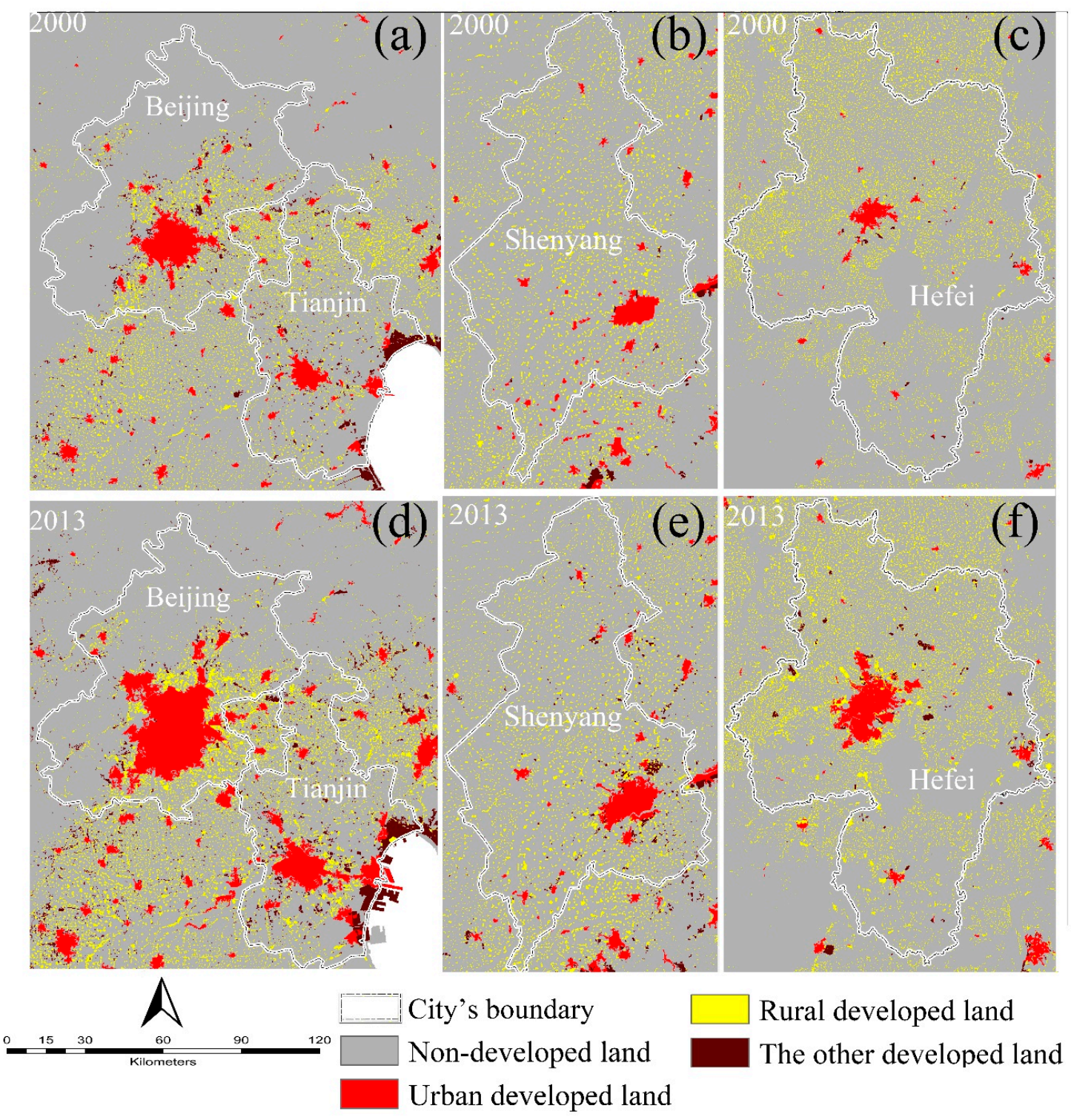

Figure 5. Dynamics of the three sub-categories of developed land in (a,d) Beijing, (b,e) Shenyang, and (c,f) Hefei in 2000 and 2013, respectively. 

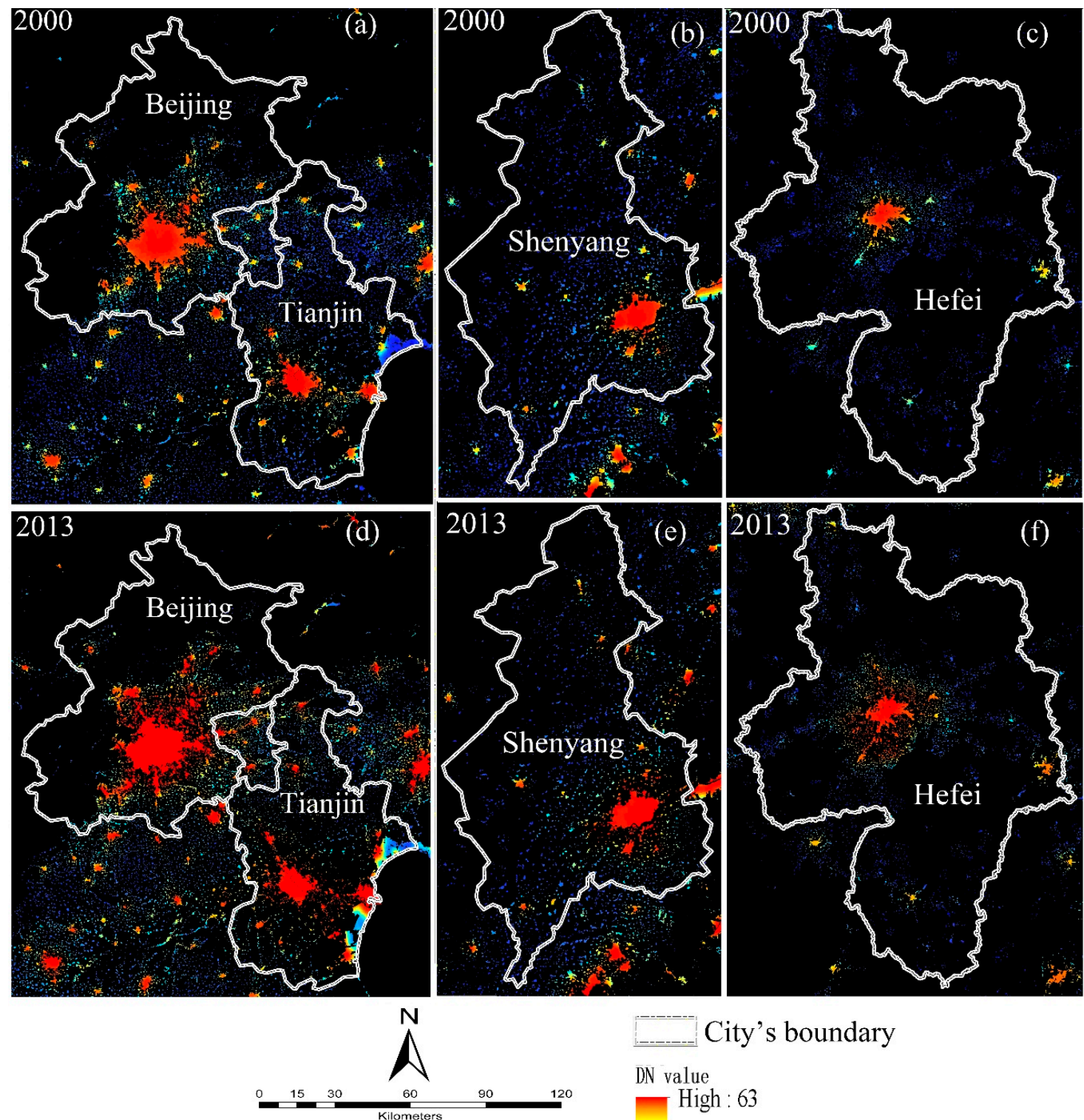

City's boundary

DN value

High : 63

Low : 0

Figure 6. The changing DN values of the three sub-categories of lit areas highlighting the spatial extent of the lit area within the boundary of representative cities (a,d) Beijing, (b,e) Shenyang, and (c,f) Hefei in 2000 and 2013, respectively. 


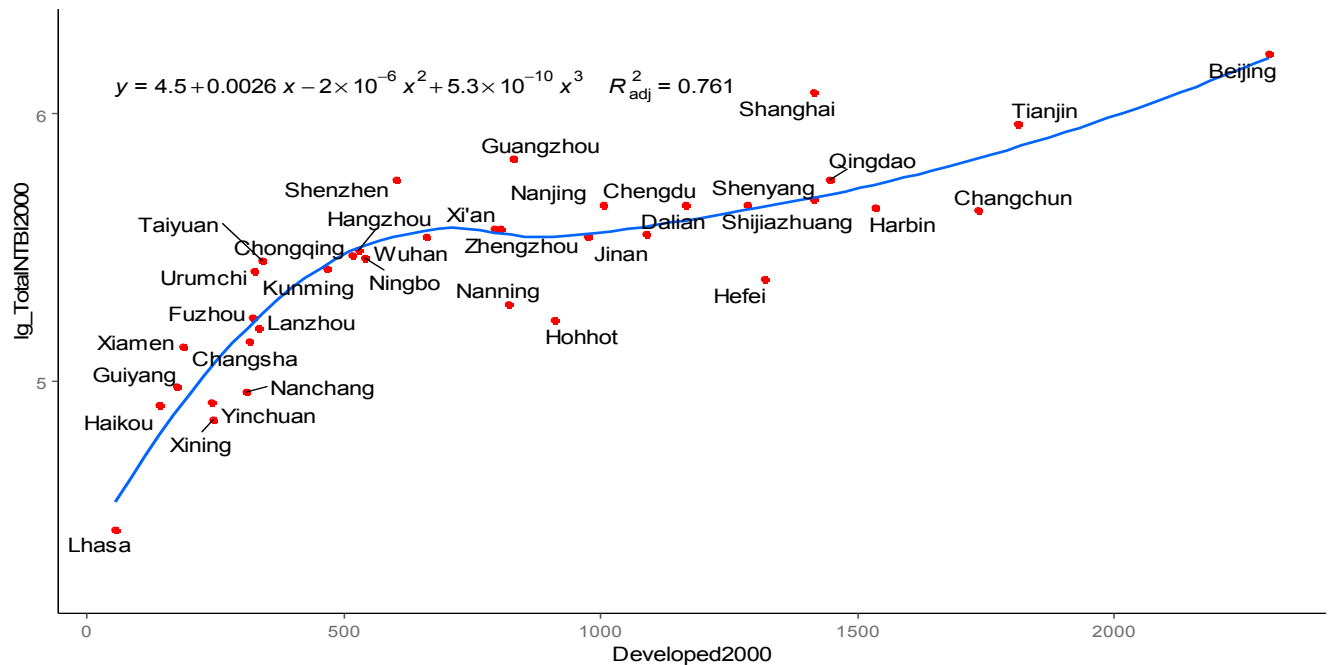

(a)

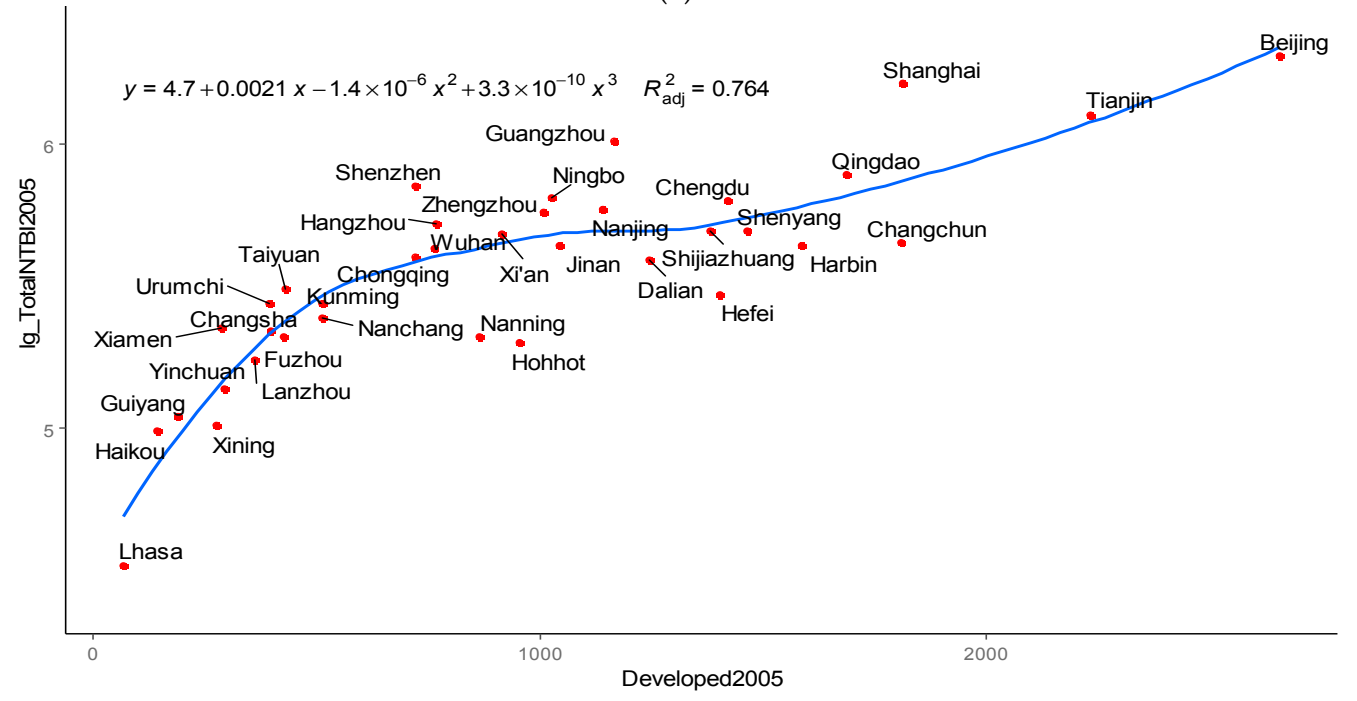

(b)

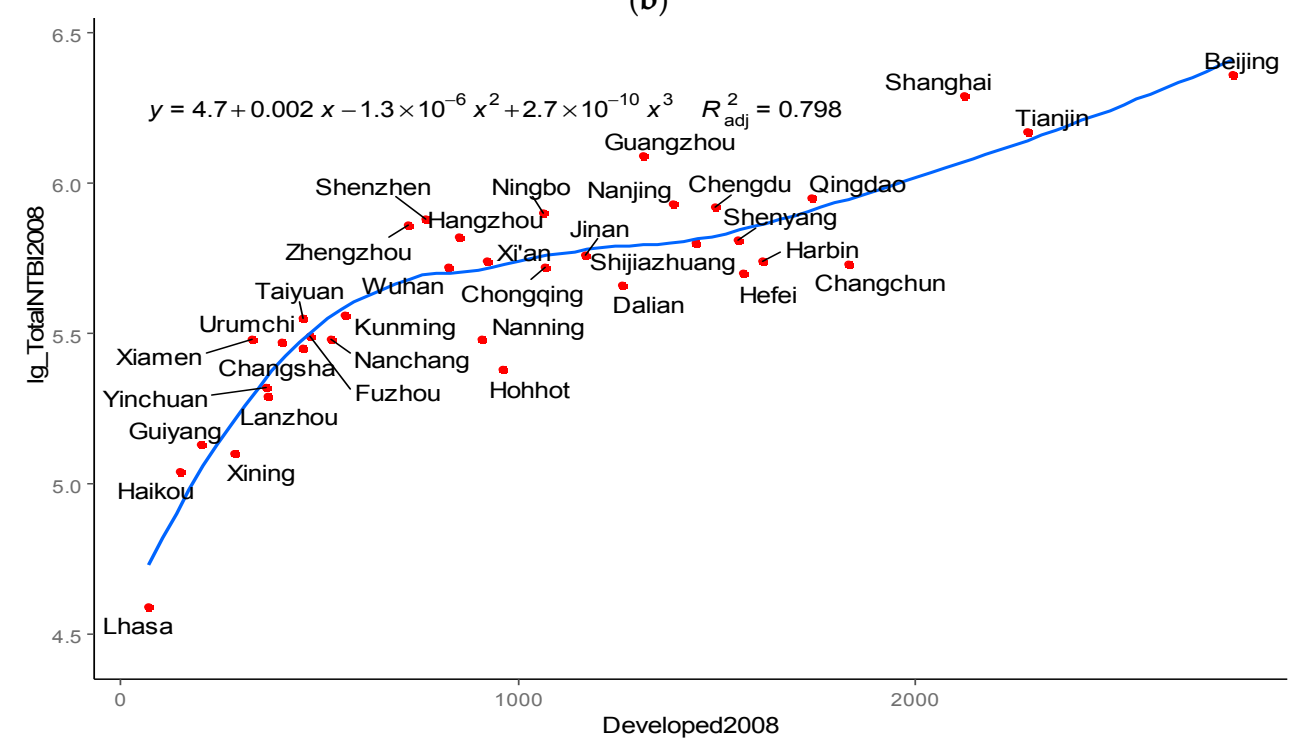

(c)

Figure 7. Cont. 


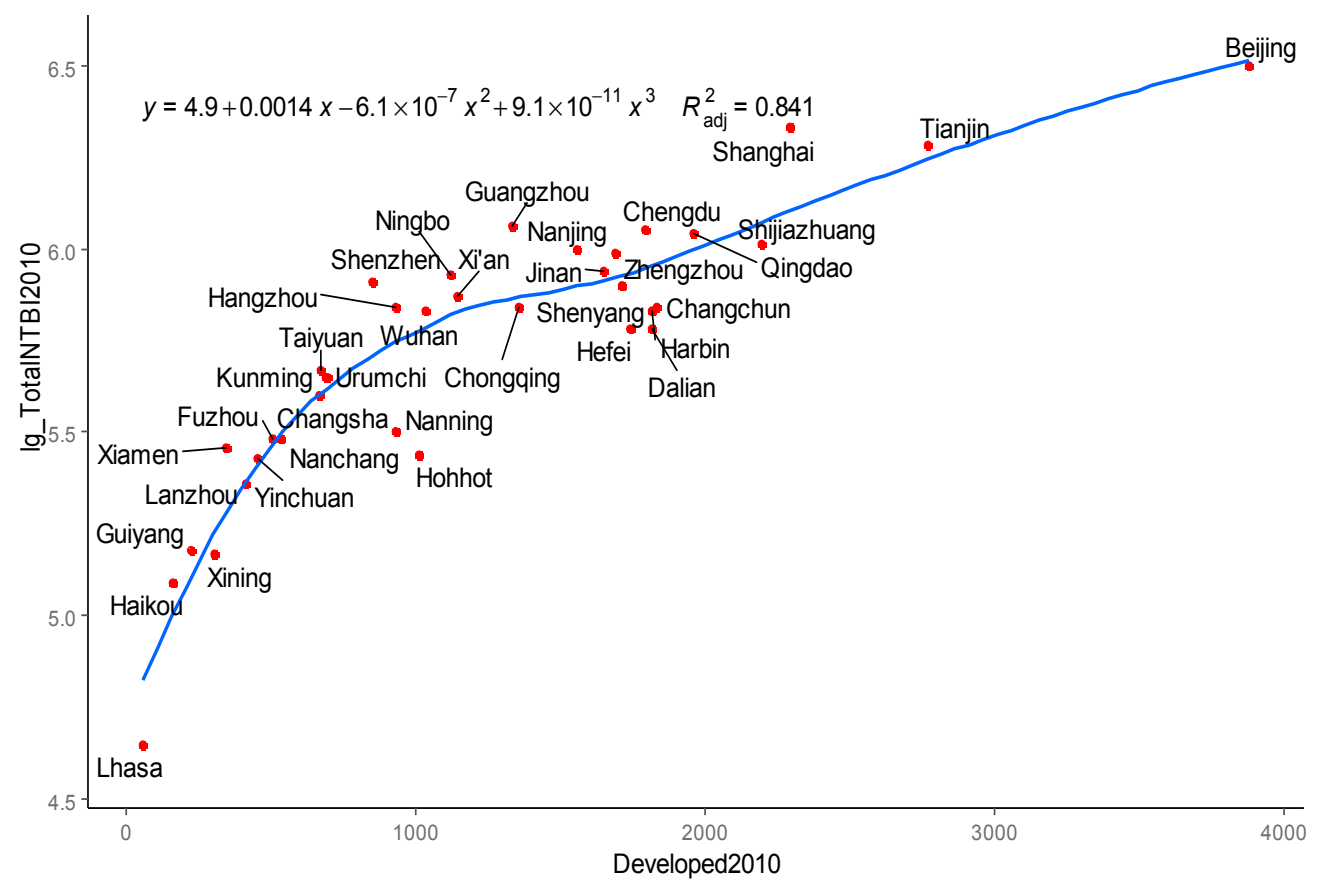

(d)

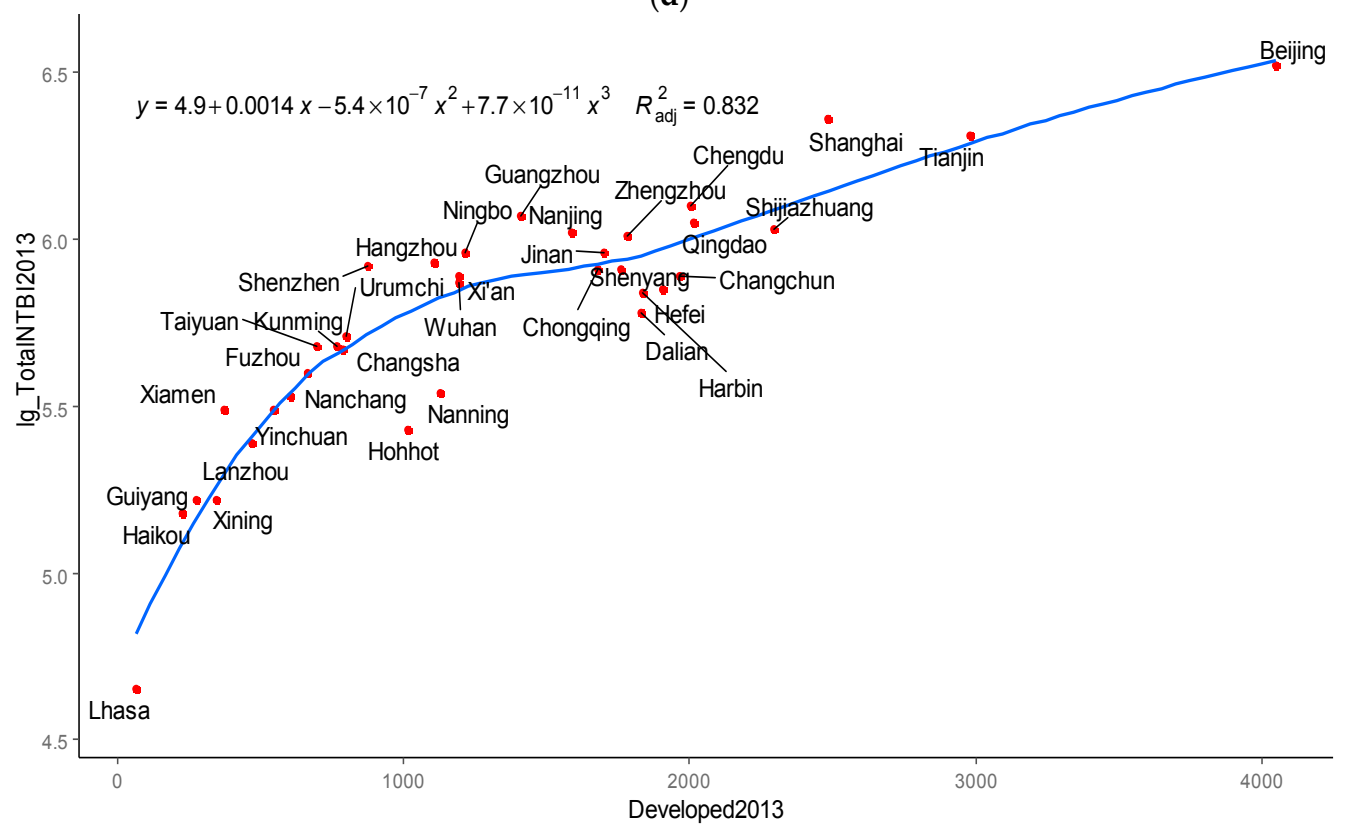

(e)

Figure 7. Relationship between total developed land area and common logarithm TotalNTBI (lg_TotalNTBI) in (a) 2000, (b) 2005, (c) 2008, (d) 2010, and (e) 2013. Total developed land area was in $\mathrm{km}^{2}$ and $\mathrm{lg}$ _TotalNTBI was in cumulative unitless DN value (CUDV). The fitted blue line denotes the trendline.

\subsection{Driving Factors Underlying the Relationship Between Developed Land Area and Associated TotalNTBI}

Table 3 exhibits the result of panel regression for the fix effects estimator. The result of the Hausman test $\left(x^{2}=34.079, \mathrm{df}=6, p<0.05\right)$ indicates a significant difference between the random and fixed effects specifications. Thus, the fixed effects estimator was adopted. The regression interpreted that approximately $71.8 \%$ of the variance of total developed land area is related to the six socioeconomic variables. POP exhibited the highest coefficient, followed by GDP and Secondary, while Tertiary 
was marginally significant. However, the coefficients for Mileage and Freight were both insignificant. Figure 8 shows that, except for several leading cities such as Beijing, Tianjin, Shanghai, Nanjing, and Guangzhou, the cities exhibited considerable inconsistency among the independent variables. For instance, Lhasa, Hohhot, and Haikou showed reasonably higher Tertiary but with relatively lower levels of GDP, POP, Mileage, and Freight. Another example is Chongqing, which showed relatively higher POP, Secondary, Mileage, and Freight but lower GDP and Tertiary. Even in the well-developed port cities, such as Ningbo and Qingdao, inconsistency existed among Mileage, Freight, POP, and Secondary. The remarkable inconsistencies between the independent variables reduced the interpretation power of Tertiary, Mileage, and Freight.

Table 3. Fixed effects estimator of the panel regression (dependent variable: Developed).

\begin{tabular}{ccccc}
\hline Coefficient & Estimate & Standard Error & $\mathbf{t}$ & $p$-Value \\
\hline Intercept & -0.090 & 0.070 & -1.284 & 0.201 \\
GDP & 0.351 & 0.049 & 7.179 & $<0.05$ \\
POP & 0.416 & 0.098 & 4.230 & $<0.05$ \\
Secondary & 0.207 & 0.065 & 3.192 & $<0.05$ \\
Tertiary & 0.125 & 0.066 & 1.885 & 0.061 \\
Mileage & -0.009 & 0.074 & -0.120 & 0.904 \\
Freight & -0.020 & 0.042 & -0.483 & 0.630 \\
\hline \multicolumn{5}{c}{ Summary statistics } \\
\hline
\end{tabular}

Table 4 exhibits the result of panel regression for the random effects estimator, verified by the result of the Hausman test (TotalNTBI, $\chi^{2}=11.833, \mathrm{df}=7, p=0.106$ ). The adopted regression interpreted approximately $92.4 \%$ of the variance of TotalNTBI as being in response to the changing independent variables. Judged by the coefficients, total developed land area appears to be the most important driver, followed in decreasing order by GDP, POP, Secondary, and Tertiary. Similar to what is shown in Table 3, Mileage and Freight were insignificant. The standardized values of the inter-city socioeconomic variables in Figure 6 also help interpret the statistical insignificance of these two variables.

Table 4. Random effects estimator of the panel regression (dependent variable: TotalNTBI).

\begin{tabular}{ccccc}
\hline Coefficient & Estimate & Standard Error & $\mathbf{t}$ & $\boldsymbol{p}$ \\
\hline Intercept & 4.044 & 0.062 & 65.121 & $<0.05$ \\
GDP & 0.642 & 0.117 & 5.464 & $<0.05$ \\
POP & 0.448 & 0.162 & 2.769 & $<0.05$ \\
Secondary & 0.544 & 0.103 & 5.274 & $<0.05$ \\
Tertiary & -0.482 & 0.110 & -4.375 & $<0.05$ \\
Freight & 0.134 & 0.107 & 1.259 & 0.210 \\
Mileage & 0.213 & 0.131 & 1.627 & 0.106 \\
Developed & 1.760 & 0.140 & 12.608 & $<0.05$ \\
\hline \multicolumn{5}{c}{ Summary statistics } \\
\hline
\end{tabular}




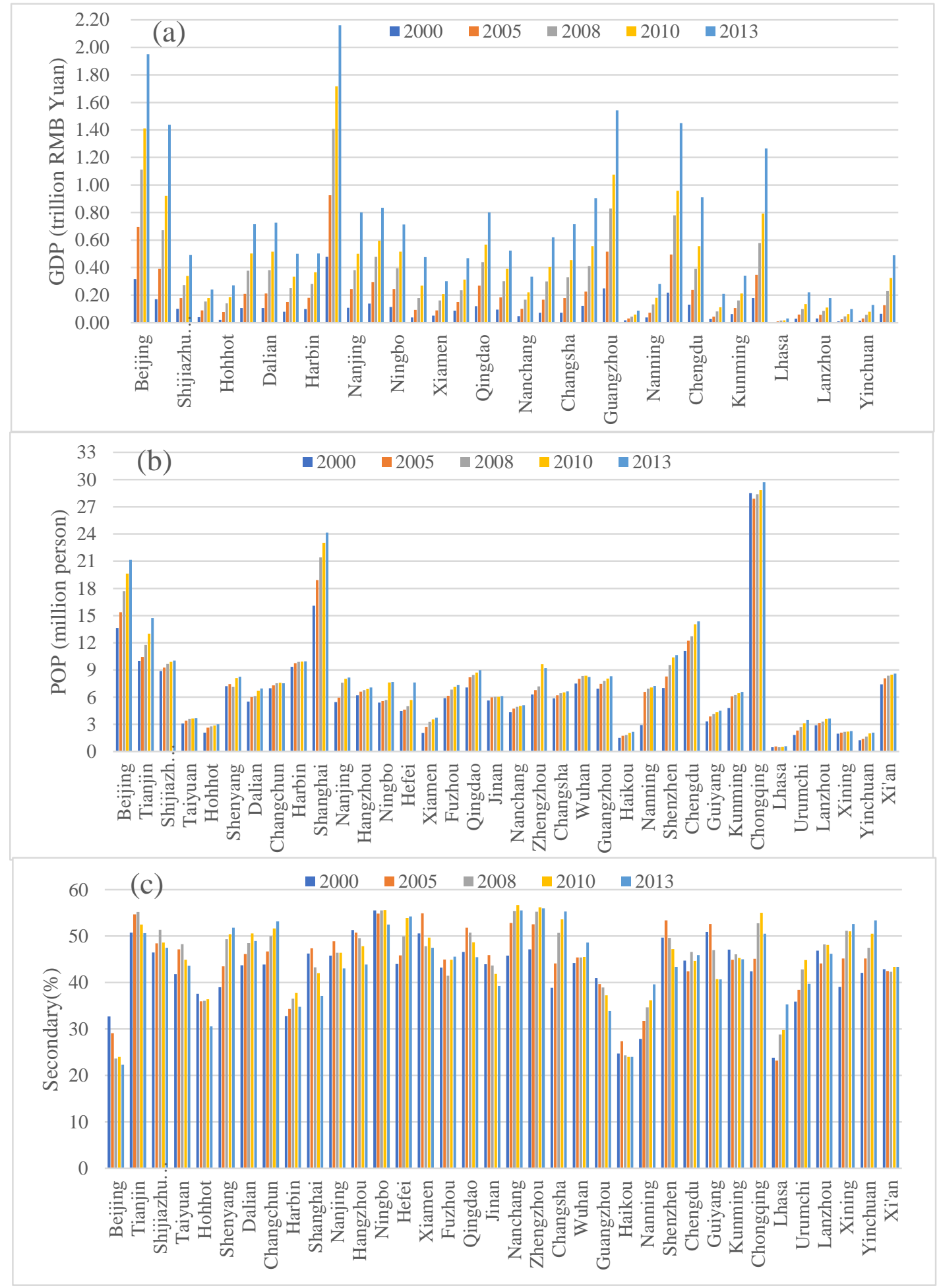

Figure 8. Cont. 


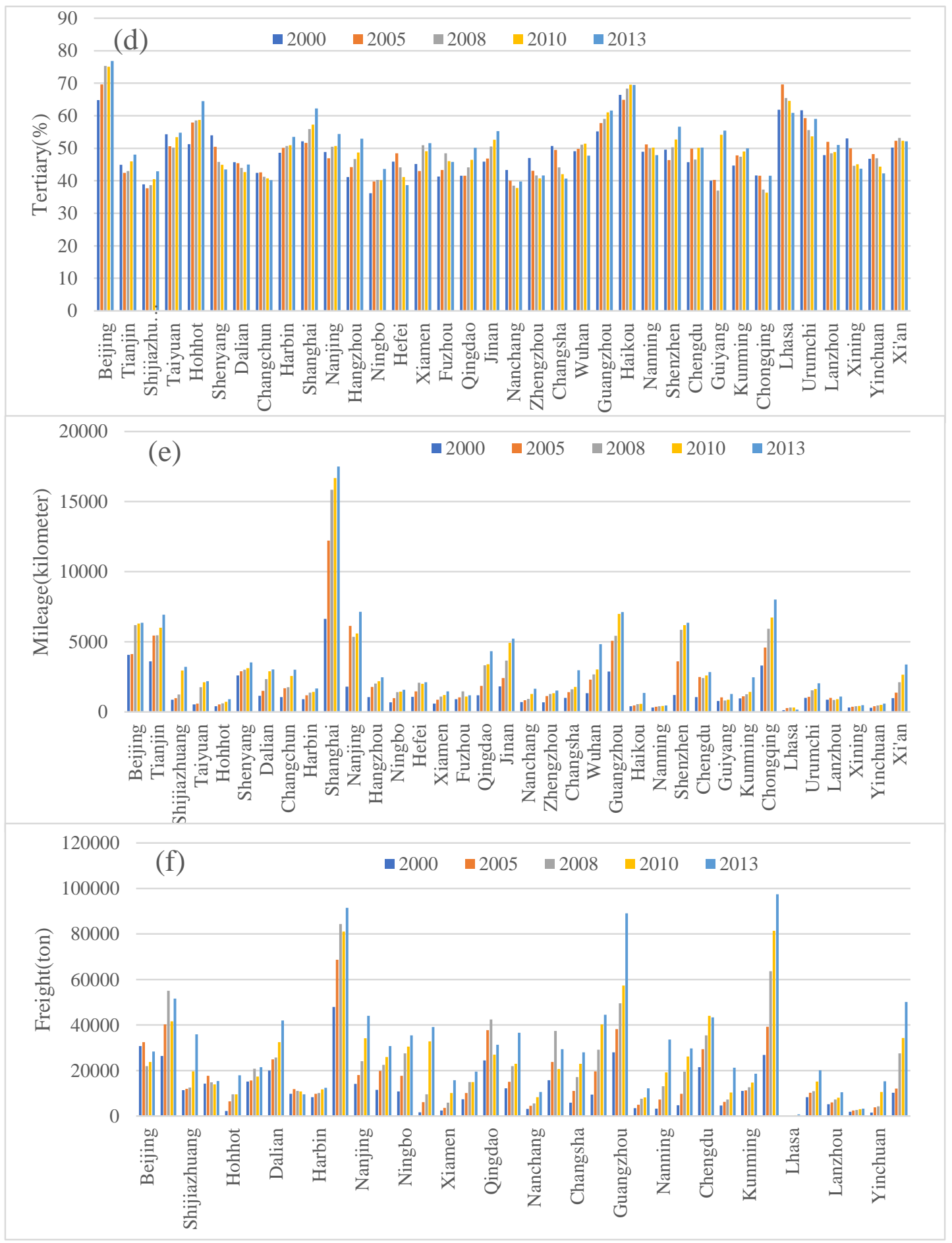

Figure 8. Six socioeconomic variables of various cities in (a) 2000, (b) 2005, (c) 2008, (d) 2010, and (e) 2013.

Further, Figure 9, in a broader sense, highlights the complicated direct and indirect effects of the independent variables and their influences on the TotalNTBI. Table 5 summarizes the coefficients of SEM, all of which were statistically significant at the $5 \%$ level. When examining the independent variables' influence on the developed land, GDP has the strongest positive coefficient of direct influence offset by the strongest negative coefficient of indirect influence, yielding a total coefficient with a positive value. POP has a relatively modest positive coefficient of direct influence, reinforced by the relatively stronger positive coefficient of indirect influence. Secondary has the stronger positive 
coefficient of direct influence offset by the relatively modest negative coefficient of indirect influence. The other three independent variables mainly have stronger negative coefficients of direct influence and fairly modest coefficients of indirect influence. They yield relatively stronger total coefficients with a negative value, which can partly be attributed to the unbalanced development level among these key cities. When examining the independent variables' influence on TotalNTBI, GDP has the second-strongest positive coefficient of direct influence, reinforced by the strongest positive coefficient of indirect influence, yielding a total coefficient with the highest positive value. Total developed land has the strongest positive coefficient of direct influence but generates the second-highest total coefficient, followed by the total positive coefficients of Tertiary, POP, Secondary, and Mileage. Freight has a relatively stronger negative coefficient of direct influence, reinforced by a relatively modest negative coefficient direct influence. Freight has a relatively stronger total coefficient with a negative value. Overall, the SEM results were generally consistent with those in Tables 3 and 4 .

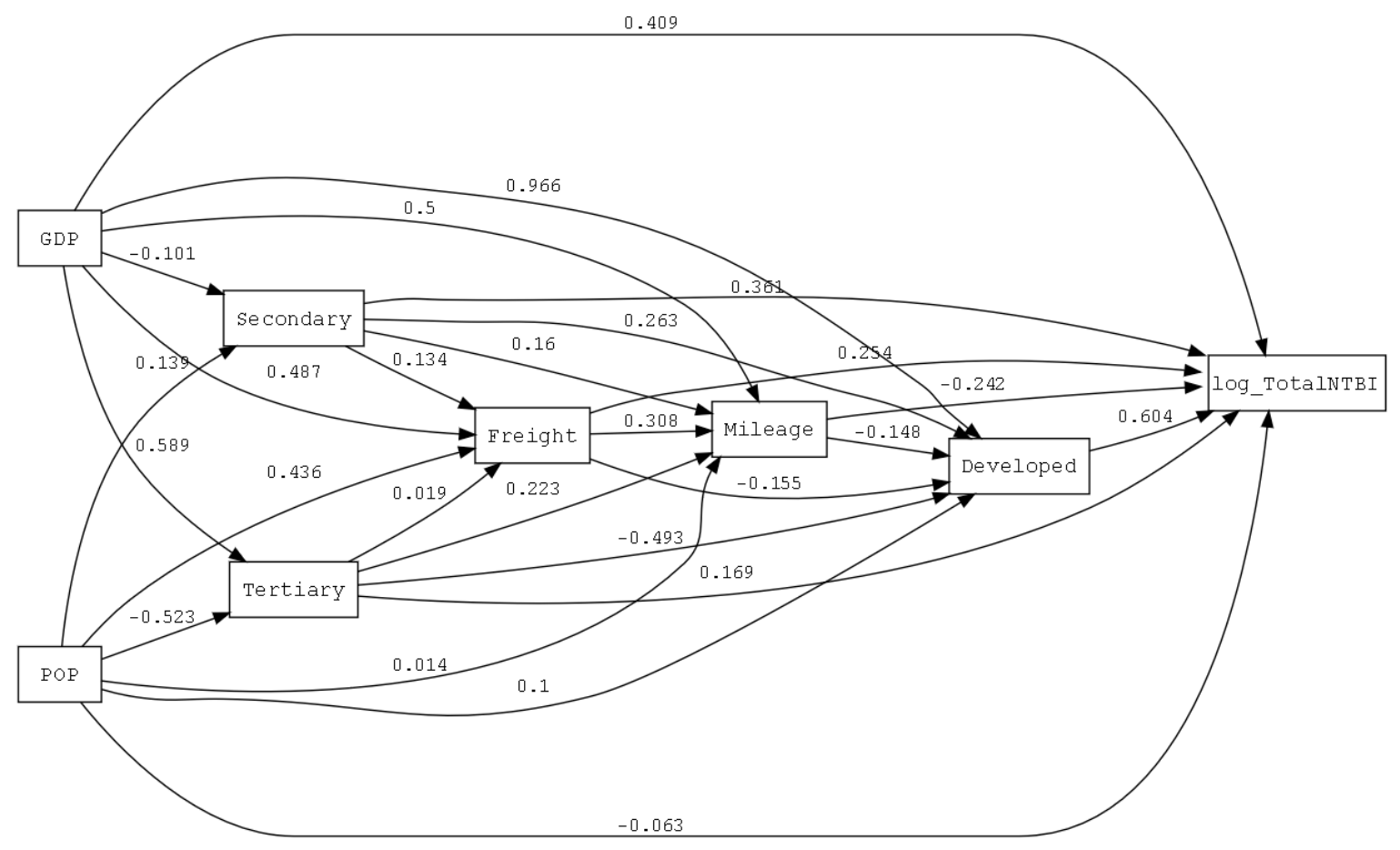

Figure 9. Path diagram of the direct/indirect effects of factors in the structural equation model (SEM). Note: The numbers above the arrowed lines denote direct coefficients.

Table 5. Summarized coefficients of SEM.

\begin{tabular}{|c|c|c|c|c|c|c|}
\hline \multirow{2}{*}{$\begin{array}{c}\text { Independent } \\
\text { Variable }\end{array}$} & \multicolumn{3}{|c|}{ Developed } & \multicolumn{3}{|c|}{ TotalNTBI } \\
\hline & $\begin{array}{c}\text { Direct } \\
\text { Coefficient }\end{array}$ & $\begin{array}{c}\text { Indirect } \\
\text { Coefficient }\end{array}$ & $\begin{array}{c}\text { Total } \\
\text { Coefficient }\end{array}$ & $\begin{array}{c}\text { Direct } \\
\text { Coefficient }\end{array}$ & $\begin{array}{c}\text { Indirect } \\
\text { Coefficient }\end{array}$ & $\begin{array}{c}\text { Total } \\
\text { Coefficient }\end{array}$ \\
\hline GDP & 0.966 & -0.416 & 0.550 & 0.409 & 0.351 & 0.760 \\
\hline POP & 0.100 & 0.238 & 0.338 & 0.07 & 0.256 & 0.263 \\
\hline Secondary & 0.263 & -0.027 & 0.236 & 0.361 & -0.213 & 0.148 \\
\hline Tertiary & -0.493 & 0.033 & -0.460 & 0.169 & 0.026 & 0.195 \\
\hline Mileage & -0.155 & -0.046 & -0.201 & 0.254 & -0.196 & 0.058 \\
\hline Freight & -0.148 & 0.000 & -0.148 & -0.242 & -0.089 & -0.331 \\
\hline Developed & - & - & - & 0.604 & 0.000 & 0.604 \\
\hline \multicolumn{7}{|c|}{ Summary statistics $X^{2}=100.616, \mathrm{df}=3, p<0.01$} \\
\hline
\end{tabular}




\section{Discussion}

\subsection{Uncertainty in Enhanced DMSP/OLS Due to Data Sources and Methods}

The application of corrected DMSP/OLS nighttime data with stable lights has been welldocumented [4-29]. Publicly accessible corrected DMSP/OLS nighttime data are also available [38,39]. We found that the corrected DMSP/OLS data adopted in the existing literature is too coarse to capture the features of developed land and associated nighttime brightness indices. As the provided DMSP/OLS nighttime data used for this study were unitless, the absolute correction of the data was impossible. Alternatively, the enhanced DMSP/OLS data provided relatively accurate information on artificial light emissions by decreasing the bias due to the brightness of rural areas and background landscapes. We partly enhanced the visual quality of DMSP/OLS data by sharpening the edges of the pixels given the limitation of the spatial resolution of land cover products and the consequent error in the misclassification of land cover categories. To some extent, our methods may also cause loss or exaggeration of brightness in urban centers and intensive rural settlements. Another problem is the corrected DMSP/OLS nighttime data is not comparable across different regions due to varying physical environment and socioeconomic conditions [40]. This problem undoubtedly complicates the difficulty in correcting such data. Therefore, for different regions, to recognize the extent of the lit area and validate the results requires a careful setting of NTBI thresholds [41] associated with three sub-categories of developed land area and socioeconomic conditions.

\subsection{Relationship Between Developed Land Area and Associated NTLEs}

Human activities, especially the intensity and magnitude of economic activities occurring on multi-scales, determine the spatiotemporal pattern and areal extent of developed land. Usually, the spatiotemporal pattern of a lit area characterized by NTLEs agrees with that of developed land. Our results are consistent with some case studies [41-47]. One of the significant shortcomings of previous studies is ignorance of the linkage between the three sub-categories of developed land area and associated NTBIs. For a specific region, changes in the growth patterns of the three sub-categories of developed land area and associated NTBIs revealed the intra-city consistency or inconsistency between human activities and related socioeconomic and environmental impacts. These changes in growth patterns imply variation in infrastructure service, urban-rural disparity, and intensity of human activities, which are usually characterized by sparse or dense human settlements and facilities. Such intra-city consistency/inconsistency can help interpret the causes of inter-city differentiation in total developed land and associated TotalNTBIs. The panel regression allowed us to quantitatively examine the partial effects of selected factors on the variance in the inter-city total developed land and the associated TotalNTBI. The simplified SEM revealed the complicated direct/indirect paths linking the driving factors and the dependent variables. Compared with previous publications, our findings can provide a different viewpoint on the relationship between the total developed land area and the associated TotalNTBI. However, our present knowledge of the mechanism underlying this relationship is somewhat limited, given the sophisticated linkages between various stakeholders. In this study, 36 Chinese cities were ranked in the present administrative system. The city boundaries vary widely according to the complicated socioeconomic and political conditions. The tightly or loosely organized central cities and surrounding junior cities and rural regions inevitably affect the variation in human activities and therefore determine the cause-effect relationship between the total developed land area and the associated TotalNTBI. For example, as shown in Figure 7, among China's four municipalities directly under the central government, Chongqing showed an outlier in the cause-effect curve, due to its spatially loose relationship between several urban clusters and vast rural regions. In this case, the inconsistency between relatively higher variables (POP, Secondary, Mileage, and Freight) and lower variables (GDP and Tertiary) in Chongqing are mainly attributed to the political arrangement rather than identifying functional geographic cities. Thus, analyses on how the driving factors influence the 
cause-effect relationship need decision-makers and researchers to collaborate in fields ranging from economy, geography, sociology, governance, urban planning, and land development.

\subsection{Implications}

In this study, we presented the overall increasing trends in both the developed land area and the associated NTBIs of China's 36 key cities, visually reflecting the urbanization process and developmental inequality between different regions [43]. Benefiting from their role in national prefecture ranks, most of these key cities are the preferred destination for intra- and inter-provincial migrators, and international investors, therefore dominating the overall patterns of population agglomeration and capital flow within the national prefecture framework [48]. There were considerable variations in the growth patterns of the developed land area and the associated NTBIs among these cities. Aside from physiographic conditions, these variations can be largely explained by the spatiotemporal heterogeneity in human agglomeration and land development intensity driven by developmental inequality.

Notably, the huge gap in economic development between the coastal and inland provinces caused large-scale migration from the less-developed western, southwestern, and middle regions to the well-developed north plain and coastal regions. The main cities, such as Beijing, Tianjin, Shanghai, Nanjing, Hangzhou, Ningbo, Guangzhou, and Shenzhen, which are the international or domestic leading cities that are highly competitive, have attracted enormous amounts of investment for developing the infrastructure to enhance urban capacity, house the increasing population, accelerate industrial restructuring, and reduce rural-urban disparity. To increase land supply and meet the demand for land development, local authorities strongly supported the amalgamation of administrative boundaries via merging urban districts and neighboring counties, triggering large-scale LULC change from natural and semi-natural land to the sprawling developed land, subsequently increasing the intensively lit area.

In contrast to the abovementioned growing cities with increasing NTBIs, several anomalies of the developed land area and the associated NTBIs occurred in both less- and well-developed regions. The first anomaly was hollowing rural settlements, characterized by decreasing RuralNTBI in rural regions. This phenomenon occurred nationwide from less-developed western and southwestern regions to well-developed coastal provinces [49]. Amongst the complex factors that coincide with the formation of 'hollow villages', urbanization was the most important. A typical example occurring in the less-developed regions is the temporary abandonment of villages with seasonal or annual returning of inhabitants, who usually seek employment as migrant workers. An extreme event was the permanent abandonment of houses because the inhabitants who preferred urban lifestyle settled in cities [50]. Another example is the observed increasing rural developed land area with decreasing RuralNTBI in the well-developed regions. As shown in Figure 4c, the dimly lit rural developed land surrounding Guangzhou and Shenzhen may be attributed to the recent winter for manufacturing. The increase in the cost of power, raw materials, and land exacerbated the enterprise's profit margin. Consequently, the intensive decrease in investment and industrial relocation elsewhere triggered the large-scale movement of migrant workers to the other cities [51-56]. The third anomaly is known as the 'ghost city', which is a unique phenomenon different from the previously known withering cities due to exhausted resources and the associated industrial decline. A ghost city usually refers to real estate built in rural areas that have since been deserted and are characterized by many vacant buildings and a dimly lit area over a considerable amount of time, i.e., several years. This phenomenon highlights the low efficiency of land development in terms of both economy and environment, considering that the creation of infrastructure outpaced the population size, subsequently causing a loss of arable land $[22,57]$.

Thus, we argue that the development of China's fast-growing megacities with massively lit areas is not the right pattern for sustainable human settlements, nor are the hollowing rural settlements and ghost cities with dim illumination at nighttime, given the conflict between large population and 
land scarcity. In terms of economy and environment, practical methods of reducing developmental inequality among different regions include improving the efficiency of land development and optimizing the delivery of infrastructure services to urban and rural areas. Theoretically, the methods adopted for quantifying the relationship between the developed land area and the associated NTBIs can be applied to any region of interest for characterizing developmental inequality among different regions, by comparing the time series of the city- and region-specific socioeconomic level, the developed land area, and the associated NTBIs. The freely available satellite nighttime light imagery (e.g., the USA's DMSP/OLS and VIIRS, and China's Luojia-1), global land cover data (e.g., China's GLOBELAND30), and accessible census data (e.g., datasets released by UNDP and FAO) reinforce the practicability of our methods.

\section{Conclusions}

In this study, 36 cities were used as a case study to investigate the relationship between developed land area and NTLEs during China's rapid urbanization. We combined socioeconomic variables, LULC data, and enhanced DMSP/OLS nighttime light data with sharpened pixel edges. Our findings can be summarized as follows.

Firstly, total developed land increased by $64.53 \%$ from $28,948 \mathrm{~km}^{2}$ in 2000 to $47,627 \mathrm{~km}^{2}$ in 2013. However, the growth patterns varied considerably among the cities. Noticeable differences in the growth patterns of the three sub-categories of developed land (urban, rural, and other developed lands) were observed.

Secondly, in response to the growth in developed land, TotalNTBI increased by $146.29 \%$ from a CUDV of $1156.74 \times 10^{4}$ in 2000 to one of $2849.05 \times 10^{4}$ in 2013. The overall trend in TotalNTBI agreed with that of total developed land (mean adjusted $R^{2}=0.799$ ). Both areas of urban developed land and other developed land agreed with their associated sub-level NTBIs. However, a relatively weak relationship was found between the rural developed land area and the associated RuralNTBI. This finding may explain the mismatched relationship between the total developed land area and the associated TotalNTBI in some cities, whose rural developed land was larger than their urban developed land.

Thirdly, the panel regression model with a fixed effect estimator or a random effect estimator showed that socioeconomic variables interpret approximately $71.8 \%$ and $92.4 \%$ of the variance in total developed land and TotalNTBI, respectively. The SEM revealed both direct and indirect influences of socioeconomic variables on total developed land, and those of the combined effects of socioeconomic variables and total developed land area on TotalNTBI. Panel regression results were generally consistent with those of SEM, though the coefficients of some socioeconomic variables were puzzling probably due to the unbalanced development of these cities. Beyond estimating the polynomial regression relationship between the total developed land area and the associated TotalNTBI, panel regression models and SEM provide more insight into the relationship between the total developed land and the associated TotalNTBI.

Our findings helped to better understand the heterogeneous processes of growth patterns of developed land and the changing lit area characterized by the TotalNTBI and sub-level NTBIs. Thus, this study provided useful information for decision-makers and researchers engaged in sustainable land development, urban management, and regional developmental inequality.

Supplementary Materials: The following are available online at http:/ /www.mdpi.com/2072-4292/11/1/10/s1.

Author Contributions: H.-m.L. and H.Z. performed data analysis; X.-g.L. performed data curation; H.Z. conceived the idea of this research and wrote this manuscript. X.-y.Y. and H.Z. reviewed and edited this manuscript.

Funding: This research was funded by the Original and Innovatory Research Program (2017-2019) of Fudan University.

Acknowledgments: We are grateful to NOAA's National Geophysical Data Center for nighttime image and data processing and to the US Air Force Weather Agency for DMSP data collection. We sincerely thank the R Foundation for Statistical Computing and numerous volunteers for supporting this comprehensive non-profitable software. In addition, we are indebted to three anonymous reviewers and the academic editor for their valuable comments and suggestions on substantially improving the quality of this manuscript. 
Conflicts of Interest: The authors declare no conflict of interest. It is a free research and the funders had no role in the design of the study, nor in the decision to publish the results.

\section{References}

1. United Nations. 2018 Revision of World Urbanization Prospects. Available online: https://www.un. org/development/desa/publications /2018-revision-of-world-urbanization-prospects.html (accessed on 20 November 2018).

2. Ellis, E.C.; Kaplan, J.O.; Fuller, D.Q.; Vavrus, S.; Goldewijk, K.K.; Verburg, P.H. Used planet: A global history. Proc. Natl. Acad. Sci. USA 2013, 110, 7978-7985. [CrossRef] [PubMed]

3. Mcdonald, R.I.; Weber, K.; Padowski, J.; Flörke, M.; Schneider, C.; Green, P.A.; Gleeson, T.; Eckman, S.; Lehner, B.; Balk, D.; et al. Water on an urban planet: Urbanization and the reach of urban water infrastructure. Glob. Environ. Chang. 2014, 27, 96-105. [CrossRef]

4. Bagan, H.; Yamagata, Y. Analysis of urban growth and estimating population density using satellite images of nighttime lights and land-use and population data. GISci. Remote Sens. 2015, 52, 765-780. [CrossRef]

5. Doll, C.N.H.; Pachauri, S. Estimating rural populations without access to electricity in developing countries through night-time light satellite imagery. Energy Policy 2010, 38, 5661-5670. [CrossRef]

6. Gibson, J.; Boe-Gibson, G.; Stichbury, G. Urban land expansion in India 1992-2012. Food Policy 2015, 56, 100-113. [CrossRef]

7. Kontgis, C.; Schneider, A.; Fox, J.; Saksena, S.; Spencer, J.H.; Castrence, M. Monitoring peri-urbanization in the greater Ho Chi Minh City metropolitan area. Appl. Geogr. 2014, 53, 377-388. [CrossRef]

8. Sharma, R.C.; Tateishi, R.; Hara, K.; Gharechelou, S.; Iizuka, K. Global mapping of urban built-up areas of year 2014 by combining MODIS multispectral data with VIIRS nighttime light data. Int. J. Digit. Earth 2016, 9, 1004-1020. [CrossRef]

9. Small, C.; Pozzi, F.; Elvidge, C.D. Spatial analysis of global urban extent from DMSP-OLS night lights. Remote Sens. Environ. 2005, 96, 277-291. [CrossRef]

10. Taubenböck, H.; Wiesner, M.; Felbier, A.; Marconcini, M.; Esch, T.; Dech, S. New dimensions of urban landscapes: The spatio-temporal evolution from a polynuclei area to a mega-region based on remote sensing data. Appl. Geogr. 2014, 47, 137-153. [CrossRef]

11. Zhou, N.; Hubacek, K.; Roberts, M. Analysis of spatial patterns of urban growth across South Asia using DMSP-OLS nighttime lights data. Appl. Geogr. 2015, 63, 292-303. [CrossRef]

12. Zhou, Y.; Smith, S.J.; Elvidge, C.D.; Zhao, K.; Thomson, A.; Imhoff, M. A cluster-based method to map urban area from DMSP/OLS nightlights. Remote Sens. Environ. 2014, 147, 173-185. [CrossRef]

13. Keola, S.; Andersson, M.; Hall, O. Monitoring economic development from space: Using nighttime light and land cover data to measure economic growth. World Dev. 2015, 66, 322-334. [CrossRef]

14. Corbane, C.; Kemper, T.; Freire, S.; Louvrier, C.; Pesaresi, M. Monitoring the Syrian Humanitarian Crisis with the JRC's Global Human Settlement Layer and Night-Time Satellite Data; Publications Office of the European Union: Luxembourg, 2016; pp. 1-14.

15. Witmer, F.W.; O'Loughlin, J. Detecting the effects of wars in the caucasus regions of Russia and Georgia using radiometrically normalized DMSP-OLS nighttime lights imagery. Mapp. Sci. Rem. Sens. 2011, 48, 478-500. [CrossRef]

16. Li, X.; Li, D.; Xu, H.; Wu, C. Intercalibration between DMSP/OLS and VIIRS night-time light images to evaluate city light dynamics of Syria's major human settlement during Syrian Civil War. Int. J. Remote Sens. 2017, 38, 5934-5951. [CrossRef]

17. Ghosh, T.; Anderson, S.J.; Elvidge, C.D.; Sutton, P.C. Using nighttime satellite imagery as a proxy measure of human well-being. Sustainability 2013, 5, 4988-5019. [CrossRef]

18. Huang, X.; Schneider, A.; Friedl, M.A. Mapping sub-pixel urban expansion in China using MODIS and DMSP/OLS nighttime lights. Remote Sens. Environ. 2016, 175, 92-108. [CrossRef]

19. Su, Y.; Chen, X.; Wang, C.; Zhang, H.; Liao, J.; Ye, Y.; Wang, C. A new method for extracting built-up urban areas using DMSP-OLS nighttime stable lights: A case study in the Pearl River Delta, southern China. Mapp. Remote Sens. 2015, 52, 218-238. [CrossRef]

20. Wang, L. Object-based spatial cluster analysis of urban landscape pattern using nighttime light satellite images: A case study of China. Int. J. Geogr. Inf. Sci. 2014, 28, 2328-2355. 
21. Wu, W.; Zhao, H.; Jiang, S. A Zipf's Law-Based Method for Mapping Urban Areas Using NPP-VIIRS Nighttime Light Data. Remote Sens. 2018, 10, 130. [CrossRef]

22. Zheng, Q.; Zeng, Y.; Deng, J.; Wang, K.; Jiang, R.; Ye, Z. “Ghost cities” identification using multi-source remote sensing datasets: A case study in Yangtze river delta. Appl. Geogr. 2017, 80, 112-121. [CrossRef]

23. Song, G.; Yu, M.; Liu, S.; Zhang, S. A dynamic model for population mapping: A methodology integrating a Monte Carlo simulation with vegetation-adjusted night-time light images. Int. J. Remote Sens. 2015, 36, 4054-4068. [CrossRef]

24. Zhuo, L.; Ichinose, T.; Zheng, J.; Chen, J.; Shi, P.J.; Li, X. Modelling the population density of China at the pixel level based on DMSP/OLS non-radiance-calibrated night-time light images. Int. J. Remote Sens. 2009, 30, 1003-1018. [CrossRef]

25. Dai, Z.; Hu, Y.; Zhao, G. The suitability of different nighttime light data for GDP estimation at different spatial scales and regional levels. Sustainability 2017, 9, 305. [CrossRef]

26. Li, C.; Li, G.; Zhu, Y.; Ge, Y.; Wu, Y. A likelihood-based spatial statistical transformation model (LBSSTM) of regional using DMSP/OLS time-series nighttime light imagery. Spat. Stat. 2017, 21, 421-439. [CrossRef]

27. Ma, T.; Zhou, C.; Pei, T.; Haynie, S.; Fan, J. Responses of Suomi-NPP VIIRS-derived nighttime lights to socioeconomic activity in China's cities. Remote Sens. Lett. 2014, 5, 165-174. [CrossRef]

28. Wang, W.; Cheng, H.; Zhang, L. Poverty assessment using DMSP/OLS night-time light satellite imagery at a provincial scale in China. Adv. Space Res. 2012, 49, 1253-1264. [CrossRef]

29. Wu, R.; Yang, D.; Dong, J.; Zhang, L.; Xia, F. Regional Inequality in China Based on NPP-VIIRS Night-Time Light Imagery. Remote Sens. 2018, 10, 240. [CrossRef]

30. Kuffer, M.; Pfeffer, K.; Sliuzas, R.; Taubenböck, H.; Baud, I.; Maarseveen, M.V. Capturing the urban divide in nighttime light images from the international space station. IEEE J. Sel. Top. Appl. Earth Obs. Remote Sens. 2018, 99, 1-9. [CrossRef]

31. China National Statistical Bureau. China National Statistical Yearbook 2014; China Statistical Press: Beijing, China, 2014.

32. Elvidge, C.; Keith, D.; Tuttle, B.; Baugh, K. Spectral identification of lighting type and character. Sensors 2010, 10, 3961-3988. [CrossRef] [PubMed]

33. Zhang, Q.; Seto, K.C. Mapping urbanization dynamics at regional and global scales using multi-temporal DMSP/OLS nighttime light data. Remote Sens. Environ. 2011, 115, 2320-2329. [CrossRef]

34. Elvidge, C.D.; Ziskin, D.; Baugh, K.E.; Tuttle, B.T.; Ghosh, T.; Pack, D.W.; Erwin, E.H.; Zhizhin, M. A fifteen-year record of global natural gas flaring derived from satellite data. Energies 2009, 2, 595-622. [CrossRef]

35. General Administration of Quality Supervision, Inspection and Quarantine of China; Standardiation Administration of China. National Standard for Current Land Use Classification (GB/T 21010-2007); Standards Press of China: Beijing, China, 2017.

36. Huang, Q.; Yang, X.; Gao, B.; Yang, Y.; Zhao, Y. Application of DMSP/OLS Nighttime Light Images: A Meta-Analysis and a Systematic Literature Review. Remote Sens. 2014, 6, 6844-6866. [CrossRef]

37. Croissant, Y.; Millo, G. Panel data econometrics in R: The PLM package. J. Stat. Softw. 2008, $27,1-43$. [CrossRef]

38. Zhang, Q.; Pandey, B.; Seto, K.C. A robust method to generate a consistent time series from DMSP/OLS nighttime light data. IEEE Trans. Geosci. Remote Sens. 2016, 54, 5821-5831. [CrossRef]

39. Yao, Y.; Chen, D.; Chen, L.; Wang, H.; Guan, Q. A time series of urban extent in China using DSMP/OLS nighttime light data. PLoS ONE 2018, 13, e0198189. [CrossRef] [PubMed]

40. Elvidge, C.D.; Tuttle, B.T.; Sutton, P.C.; Baugh, K.E.; Howard, A.T.; Milesi, C.; Bhaduri, B.; Nemani, R. Global Distribution and Density of Constructed Impervious Surfaces. Sensors 2007, 7, 1962-1979. [CrossRef] [PubMed]

41. Henderson, M.; Yeh, E.T.; Gong, P.; Elvidge, C.; Baugh, K. Validation of urban boundaries derived from global night-time satellite imagery. Int. J. Remote Sens. 2003, 24, 595-609. [CrossRef]

42. Amaral, S.; Monteiro, A.M.; Câmara, G.; Quintanilha, J.A. DMSP/OLS night-time light imagery for urban population estimates in the Brazilian Amazon. Int. J. Remote Sens. 2006, 27, 855-870. [CrossRef]

43. Florida, R.; Mellander, C.; Gulden, T. Global metropolis: Assessing economic activity in urban centers based on nighttime satellite images. Prof. Geogr. 2012, 64, 178-187. [CrossRef] 
44. Gao, B.; Huang, Q.; He, C.; Sun, Z.; Zhang, D. How does sprawl differ across cities in China? A multi-scale investigation using nighttime light and census data. Landsc. Urban Plan. 2016, 148, 89-98. [CrossRef]

45. Lo, C.P. Urban indicators of China from radiance-calibrated digital DMSP/OLS nighttime images. Ann. Assoc. Am. Geogr. 2002, 92, 225-240. [CrossRef]

46. Moreno, E.L.; Blanco, Z.G. Ghost cities and empty houses: Wasted prosperity. Am. Int. J. Soc. Sci. 2014, 3, 207-216.

47. Sutton, P.C.; Cova, T.J.; Elvidge, C.D. Mapping "exurbia" in the conterminous United States using nighttime satellite imagery. Geocarto Int. 2006, 21, 39-45. [CrossRef]

48. Wei, Y.D.; Li, H.; Yue, W. Urban land expansion and regional inequality in transitional China. Landsc. Urban Plan. 2017, 163, 17-31. [CrossRef]

49. Huang, H.; Wei, Y.D. Spatial inequality of foreign direct investment in China: Institutional change, agglomeration economies, and market access. Appl. Geogr. 2016, 69, 99-111. [CrossRef]

50. Xue, L. Study on the inner-decaying village and the Countermeasures with Jiangsu province as the case. City Plan. Rev. 2001, 25, 8-13.

51. Jiang, C. Exploration on the Governance for Guangzhou's "Hollow Villages". In Proceedings of the 4th International Conference on Education and Education Management, Singapore, 8-9 December 2014; pp. 66-70.

52. Chen, J.; Yue, Y.D. Industry agglomeration and industrial migration in China's industrialization. Syst. Eng. 2013, 31, 92-97.

53. Huang, X.F.; Yang, D. Dose industrial transfer policy contribute to the convergence between regions: An analysis based on the regression discontinuity of county data from Guangdong. Int. Econ. Trade Res. 2017, 33, 101-112.

54. Lu, H.Y. Structural adjustment trend in Pearl River Delta under the background of industrial evolution and financial crisis. Forward Pos. Econ. 2009, 9, 25-33.

55. Xu, D.Y.; Liang, Q. An analysis of the "push" and "pull" of industrial transfer in Pearl River Delta. J. Cent. Univ. Finan. Econ. 2011, 1, 68-73.

56. Yang, G. Comment on the industry selection and spatial layout of "Great South Hunan" under the background of industrial transfer. Econ. Geogr. 2014, 34, 178.

57. Sorace, C.; Hurst, W. China's phantom urbanisation and the pathology of ghost cities. Soc. Sci. Electron. Publ. 2016, 46, 1-19. [CrossRef] 